\title{
Fast, Stable Computation of Thermodynamic Properties of Ammonia-Water Mixtures
}

\author{
Alexander S. Rattner and Srinivas Garimella* \\ Sustainable Thermal Systems Laboratory, George W. Woodruff School of Mechanical \\ Engineering, Georgia Institute of Technology, Atlanta, GA 30332 \\ *Corresponding Author: \\ Phone: +1-404-894-7479 \\ Postal address: Love Building, Room 340, Ferst Drive, Atlanta, GA 30332 \\ E-mail: sgarimella@gatech.edu
}

Fax: +1-404-894-8496 


\begin{abstract}
Software implementations of thermodynamic property routines for ammonia-water mixtures are developed for refrigeration and air-conditioning applications. Saturation correlations are employed to identify single-phase state points, yielding up to a5-fold reduction in property evaluation time. A run-time database of previously evaluated state points is implemented to improve initial guesses for iterative property evaluation, reducing property evaluation time by $45 \%$ in a representative study. The property routines are implemented in a standalone program and as a compiled routine for use in MATLAB ${ }^{\circledR}$ and Simulink ${ }^{\circledR}$. Both implementations perform property evaluations significantly faster than existing software packages. Program performance is measured on a $2.2 \mathrm{GHz}$ machine, and average individual state point evaluation times were found to range from 50 to $930 \mu$ s, depending on the provided input properties. Additionally, a segmented, transient, ammonia-water absorber model is developed in Simulink ${ }^{\circledR}$ to assessthe use of the property routines for practical engineering calculations. The proposed computational techniques can be applied to accelerate property evaluationsfor other mixtures.
\end{abstract}

\title{
KEYWORDS
}

Absorption; Ammonia-water; Thermodynamic properties; Zeotropic mixtures 


\section{NOMENCLATURE}

$a, b, c, d \quad$ coefficient for empirical property expression (-)

$A, B, C, D, E, F \quad$ dimensionless coefficient for empirical property expression (-)

$A \quad$ heat transfer area, in absorber model $\left(\mathrm{m}^{2}\right)$

$c_{\mathrm{p}} \quad$ specific heat at constant pressure $\left(\mathrm{kJ} \mathrm{kg}^{-1} \mathrm{~K}^{-1}\right)$

E $\quad$ error at a specific iteration (-)

$g \quad$ specific Gibbs free energy $\left(\mathrm{kJ} \mathrm{kg}^{-1}\right)$

$h \quad$ specific enthalpy $\left(\mathrm{kJ} \mathrm{kg}^{-1}\right)$

$H$ total enthalpy, in absorber model $(\mathrm{kJ})$

$J \quad$ Jacobian matrix, in iterative solver (-)

$k$ thermal conductivity $\left(\mathrm{W} \mathrm{m}^{-1} \mathrm{~K}^{-1}\right)$

$l \quad$ segment length, in absorber model (m)

$m \quad$ segment mass, in absorber model $(\mathrm{kg})$

$\dot{m}$ mass flow rate, in absorber model $\left(\mathrm{kg} \mathrm{s}^{-1}\right)$

$M \quad$ molar mass of mixture $\left(\mathrm{kg} \mathrm{kmol}^{-1}\right)$

$P \quad$ pressure $(\mathrm{kPa})$

$Q \quad$ quality (-)

$r \quad$ residual vector, in iterative solver (-)

$R \quad$ gas constant $\left(\mathrm{kJ} \mathrm{kg}^{-1} \mathrm{~K}^{-1}\right)$

$s \quad$ specific entropy $\left(\mathrm{kJ} \mathrm{kg}^{-1} \mathrm{~K}^{-1}\right)$

$t$ time, in absorber model (s)

$T$ temperature $(\mathrm{K})$

$u \quad$ specific internal energy $\left(\mathrm{kJ} \mathrm{kg}^{-1}\right)$

$U A$ heat transfer conductance value, in segmented absorber model $\left(\mathrm{W} \mathrm{K}^{-1}\right)$

$v \quad$ specific volume $\left(\mathrm{m}^{3} \mathrm{~kg}^{-1}\right)$

$V \quad$ segment volume in absorber model $\left(\mathrm{m}^{3}\right)$

$x, y \quad$ liquid and vapor ammonia mass concentrations $\left(\mathrm{kg} \mathrm{kg}^{-1}\right)$

$\bar{x}, \bar{y} \quad$ liquid and vapor ammonia molar concentrations $\left(\mathrm{kmol} \mathrm{kmol}^{-1}\right)$

\section{Subscripts}

0 reference value for saturation correlations, and reference state in absorber model 


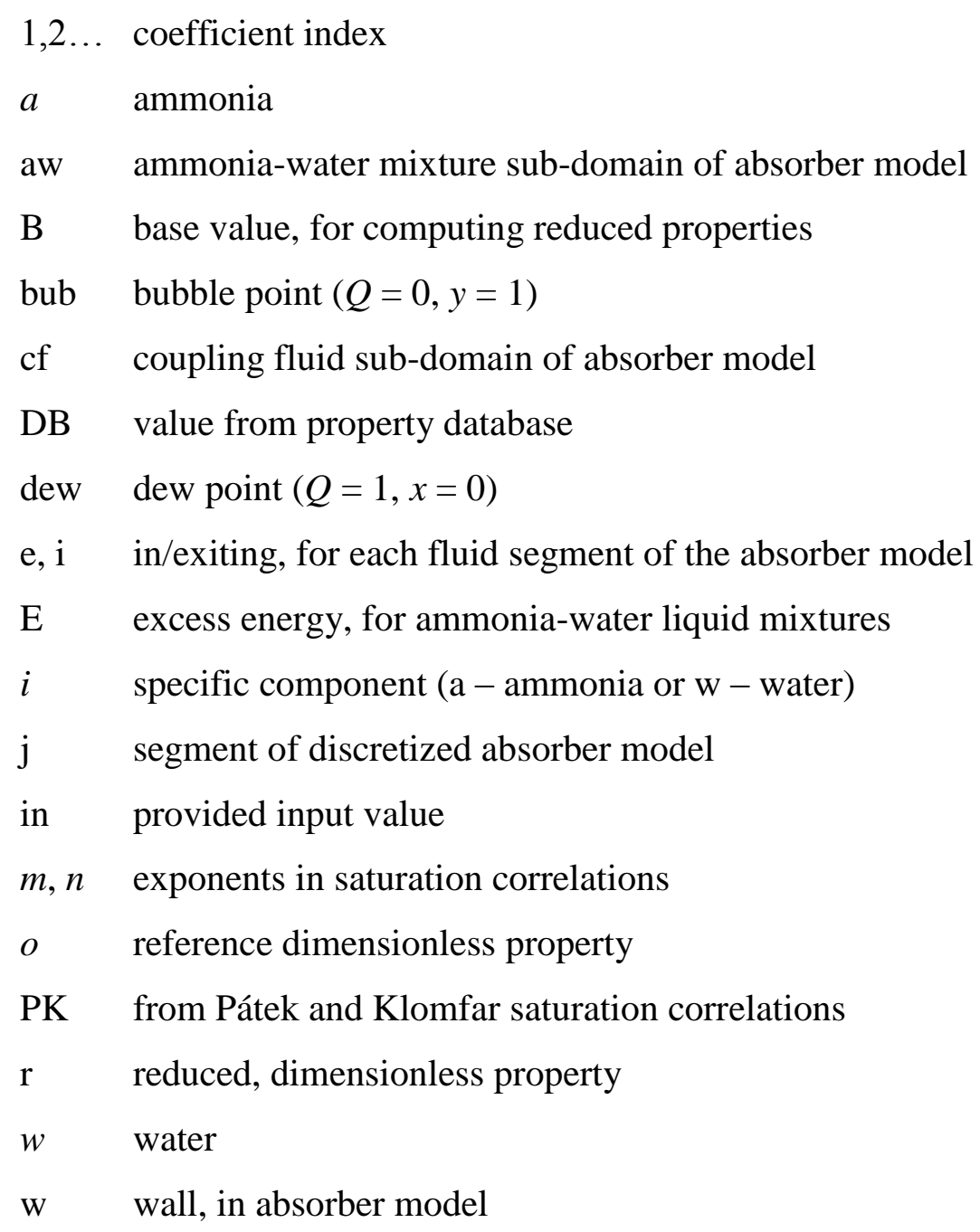

\section{Superscripts}

$0 \quad$ initial guess, for iterative solutions

g gas phase

$j \quad$ specific phase ( 1 - liquid or $\mathrm{g}-$ gas $)$

$k \quad$ current iteration

1 liquid phase

\section{Greek characters}
$\alpha \quad$ under-relaxation factor, in iterative solver
$\delta \quad$ small change in a property, for estimating derivatives
$\Delta \quad$ change in value, at each step of an iterative solver 


$$
\begin{array}{ll}
\mu & \text { chemical potential }\left(\mathrm{kJ} \mathrm{kmol}^{-1}\right) \\
\rho & \text { normalized distance from database property point, } \\
& \text { or fluid density in absorber model } \\
\phi & \text { generic thermodynamic property } \\
\psi & \text { overall (two-phase) ammonia concentration }\left(\mathrm{kg} \mathrm{kg}^{-1}\right)
\end{array}
$$




\section{Introduction}

\subsection{Background}

The ammonia-water fluid pair is employed in a broad range of energy systems including absorption refrigeration, heat pumping, and even power generation through the Kalina cycle (Heppenstall, 1998). As theseammonia-water technologies are refined, and specializedtwo-phase heat and mass exchangers are developed, the demands on thermophysical property formulations, and the software implementations thereof, are greatly increased. The major objectives in the development and implementation of property formulations are outlined below.

- Speed - While idealized steady-state thermodynamic cycle models can be solved with fewer than 20 thermodynamic state point evaluations, more complex models that account for transient system behavior and incorporate segmented component descriptions may require millions of property evaluations per simulation. Thus, expedient evaluation of such simulations is dependent on the computational cost of the underlying property routines.

- Accuracy - The desire for accurate thermodynamic properties must be weighed against computational cost to arrive at a property formulation that is suitable for a given application. The development ofaccurate ammonia-water property formulations is challenging due to the highly zeotropic nature of the fluid mixture and the difficulty of measuring vapor-phase composition. As a result, there have been substantial discrepancies between thermodynamic properties reported by different investigators (Tillner-Roth and Friend, 1998b).

- Consistency - While table interpolation or curve fits of property data may lead to fast, highaccuracy property formulations, they may still be unsuitable for certain applications. If such formulations are not thermodynamically consistent, they will lead to computational models that do not conserve mass or energy, and thus yield nonphysical results. 
- Stability - Many ammonia-water property formulations are defined implicitly, requiring iterative solution in the two-phase regime. If these are not implemented with care, certain input data sets may cause the solver to diverge or return an incorrect state point.

The ammonia-water mixture has been extensively investigated on the path to achieving these objectives - beginning with experimental measurements of the fluid pair, which have later been incorporated into algebraic correlations and equations of state suitable for evaluation on computers.

\subsection{Literature Review}

Experimental studies of the fluid pair date back to the 1860 s, but the first investigation of partial vapor pressures over the entire composition range of the mixture was conducted by Wilson (1925). Wucherer and von Druck (1932) measured fluid properties up to $1.96 \mathrm{MPa}$, and developed bubble and dew point diagrams that were used forrefrigerator design by Electrolux through the late 1960s (Almen, 2007). Due to the relatively high volatility of ammonia, the vapor fraction of water was too low to measure in many of the state points considered byWilson (1925) and Wucherer and von Druck (1932).Scatchard et al. (1947) addressed this limitation by publishing tables of numerically predicted vapor compositions based on more preciseexperimental data. Macriss et al. (1964)performedmeasurements of the mixture properties, and extended the available thermophysical property data up to $3.6 \mathrm{MPa}$. Gillespie et al. (1987) and Rizvi and Heidemann (1987) measured liquid-vapor equilibria up to critical pressures, and attempted to fill gaps in existing data and address discrepancies between earlier investigations. Comprehensive, critical reviews of experimental investigations of the thermophysical properties of ammonia-water have been compiled by Tillner-Roth and Friend (1998b) and Almen (2007). 
As the availability of computing resources improved, researchers began developing algebraic formulations for the properties of ammonia-water mixtures to replace existing graphical and tabular data. Three main approaches have been employed in the development of algebraic property formulations for ammonia-water mixtures. The first, initially proposed by Schulz (1972), develops a fundamental relation for the Gibbs free energy using four empirical equations of state for the liquid and vapor phases of both pure components and the Redlich and Kister (1948) mixing model. In this formulation, vapor-liquid equilibria are obtained by equating the chemical potentials of vapor and liquid components, which are derived from the equations of state and mixing rules. Thermodynamic properties such as enthalpy, internal energy, specific volume, and entropy are similarly obtained by manipulation of the fundamental relation. Ziegler and Trepp (1984) published an extended version of the formulation of Schulz (1972), which predictedpropertiesaccurate up to $5 \mathrm{MPa}$. Ibrahim and Klein (1993) extended the work of Ziegler and Trepp (1984) by fitting the coefficients to higher pressure data and incorporating a fugacitybasedcorrection, obtaining a thermophysical property formulation valid up to $11 \mathrm{MPa}$. A similar, empirical, fundamental-relation based formulation for the thermodynamic properties of ammonia water has also been developed by El-Sayed and Tribus(1985) for use in power cycle analysis. The empirical fundamental relation approach has seen widespread use through the freely available AMMWAT utility (Herold et al., 1988) and the $\mathrm{NH} 3 \mathrm{H} 2 \mathrm{O}$ routine incorporated into the Engineering Equation Solver (EES) software package (Klein, 2014). This approach to property evaluation has been validated for accuracy and ensures thermodynamic consistency because all properties are derived from a single equation of state. However,some investigators have suggested that the need for computationally expensive iterative solution may limit application to 
relatively simple engineering calculations (Ganesh and Srinivas, 2010; Pátek and Klomfar, 1995).

In response to the computational cost of existing formulations for the properties of ammoniawater mixtures, Pátek and Klomfar (1995) developed a set of explicit curve fits to experimental measurements for the bubble and dew temperatures, saturated vapor composition, and saturated liquid and vapor enthalpies. The correlations were shown to be accurate up to $2 \mathrm{MPa}$, however, they are not thermodynamically consistent, which may lead to problems in practical applications. For example, the predicted bubble and dew temperature surfaces intersect at representative absorption chiller condenser conditions. While the correlations of Pátek and Klomfar (1995) are presented explicitly in terms of specific sets of thermodynamic properties (e.g., $T_{\text {bub }}(P, x)$, $\left.h_{\text {dew }}(T, y)\right)$, iterative solution is still required for alternate sets of input properties (e.g., $T_{\text {bub }}(P, v)$ , $\left.h_{\text {dew }}(T, P)\right)$. Conde (2004) notes, however, that compared to other property formulations, these equations are easy to solve implicitly. Ganesh and Srinivas (2010) integrated the two-phase correlations of Pátek and Klomfar (1995) with the single-phase models of Ziegler and Trepp (1984), yielding a complete formulation for the thermodynamic properties of ammonia-water mixtures. Consistency of property data is a key limitation of this approach, as property value differences between state points may vary depending on whether they are evaluated across single- or two-phase regions.

Mejbri and Bellagi (2006)highlight the limitations of the empirical fundamental-relation approach to the calculation of ammonia-water mixture properties, such as the large number of coefficients required to obtain accurate property values ( $>60$ in the formulation of Ibrahim and Klein (1993)) and poor accuracy for extrapolation beyond the originally validated property 
regions. A third approach to the formulation of the properties of ammonia-water mixtures addresses these issues by employing equations of state based on molecular dynamics or statistical mechanics. Such first-principles based EOSs typically have fewer degrees of freedom than series-expansion based empirical EOSs, and can capture the underlying physical phenomena governing fluid behavior outside the data ranges originally used to fit coefficients. This approach was first employed byHeidemann and Rizvi (1986) with the Peng-Robinson EOS and 8 different mixing rules. Park and Sonntag (1990) developed a generalized EOS, and obtained accurate results up to $20 \mathrm{MPa}$ and $650 \mathrm{~K}$ for the ammonia-water system. Duan et al. (1996) employed an end-member EOS to obtain accurate ammonia-water mixture properties up to critical temperatures and pressures. Abovsky (1996) achieved accurate results from $0.01-30 \mathrm{MPa}$ and 200 - 700K using an EOS based on thermodynamic perturbation theory. Nowarski and Friend (1998) developed a formulation for the mixture properties using the extended corresponding states method to accurately predict fluid density. Perhaps the most successful first principles based EOS for ammonia-water mixtures was published by Tillner-Roth and Friend (1998a), with a reported range of accuracy of up to $40 \mathrm{MPa}$. In a review of formulations for the thermodynamic properties of ammonia-water mixtures, Thorin (2000) reported that the Tillner-Roth and Friend (1998a) EOS achieves better agreement than other EOSs at near-critical conditions. The following year, the International Association for the Properties of Water and Steam (Rukes and Dooley, 2001) adopted the formulation ofTillner-Roth and Friend (1998a) in its guidelines for calculating properties of the ammonia-water mixture. The US National Institute of Standards and Technology (NIST) later implemented the formulation of Tillner-Roth and Friend (1998a) in its REFPROP software (Lemmon et al., 2010). While this approach yields accurate fluid properties over a wide range of thermodynamic conditions, the NIST implementation is significantly more 
computationally expensive than the $\mathrm{NH} 3 \mathrm{H} 2 \mathrm{O}$ routine in EES, and can be unstable at nearsaturation conditions. It is unclear if these performance limitations are intrinsic to the TillnerRoth and Friend (1998a) formulation or just this implementation. A number of first-principles based formulations have been published more recently by Holcomb and Outcalt (1999), Mejbri and Bellagi (2006), and Figueira et al. (2011), among others.

\subsection{PresentEffort}

Nearly all existing property formulations for ammonia-water mixtures have been reported with detailed analyses to verify their agreement with experimental measurements in selected thermodynamic ranges. Due to the complexity and computational cost of many ammoniawatersystemsimulations, researchers often choose to sacrifice the thermodynamic consistency offered by implicit EOS property formulations for the speed of explicit correlations. However, the speed and stability of EOS formulations is strongly dependent on the implementation approach, a topic that has received limited attention in the literature. The objective of this study is to improve the speed and stability of implicit EOS formulations of the thermodynamic properties of ammonia-water mixtures by the careful selection and implementation of computational and numerical techniques. Through this approach, the viability of the many published implicit property formulations for engineering applications can be improved, and the increased speed and stability could enable more comprehensive studies of ammonia-water systems using the availablemodels.

This study adopts the empirical EOS ammonia-water mixture property formulation of Ziegler and Trepp (1984). This EOS was selected because it was validated for conditions representative of the target applications in ammonia-water absorption systems $(230 \leq T \leq 500 \mathrm{~K}$ and $20 \leq P \leq$ $5000 \mathrm{kPa}$ ), is thermodynamically consistent, and is less computationally complex than more 
recent formulations with expanded operating ranges (e.g., those of Ibrahim and Klein (1993) and Tillner-Roth and Friend (1998a)). Adiscussion of the accuracy of the thermodynamic properties, as implemented, is provided in Appendix C. A number of strategies are applied to improve the computational speed and numerical stability of the formulation including:

- Use of explicit correlations for the bubble and dew surfaces (Pátek and Klomfar, 1995) to avoid costly iterative solution of state points sufficiently far from the 2-phase region

- Maintaining a run-time database of previously evaluated state points to improve initial guesses for iterative solution, reducing iteration count and the possibility of solution divergence

- Careful selection of under-relaxation and limiter parameters in the iterative solvers to reduce iteration count and avoid solution divergence

The implemented ammonia-water property routinesare profiled using randomly generated sets of thermodynamic state points representative of conditions in absorption refrigeration and heat pumping applications. Performance studies are conducted to compare these routines with those in commercially available software packages. Additionally, the routines are incorporated into a transient, segmented ammonia-water absorber model to demonstrate the performance in practical engineering calculations.

\section{Thermodynamic property formulation and implementation}

\subsection{Implementation of Thermodynamic Property Library}

The ammonia-water mixture thermodynamic property routines developed in this studyuse the formulation of Ziegler and Trepp (1984), which is presented in Appendix A. These routines support property evaluation for input triples of $(T, P, \psi),(T, P, Q),(T, \psi, v),(P, \psi, h),(P, \psi, Q)$, 
After initialization and population of the property data structures, the mixture library is ready

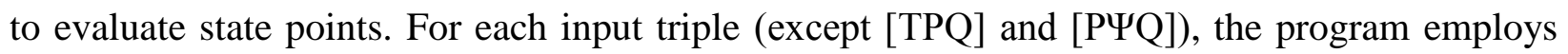
bounds based on computationally inexpensivesaturation correlations (Pátek and Klomfar, 1995) to determine if the state point is definitely in a single-phase region and if explicit or relatively fast implicit routines can be employed for property evaluation.By incorporating a margin of 2 $5 \%$ (depending on the input mode) around the saturation correlations, only state points that are sufficiently outside the saturation region are treated as single-phase, and inconsistencies between the analytically derived and correlated vapor-liquid equilibria are avoided. The margins reported in this study were manually tuned to decreaseproperty evaluation times while ensuring that two- 


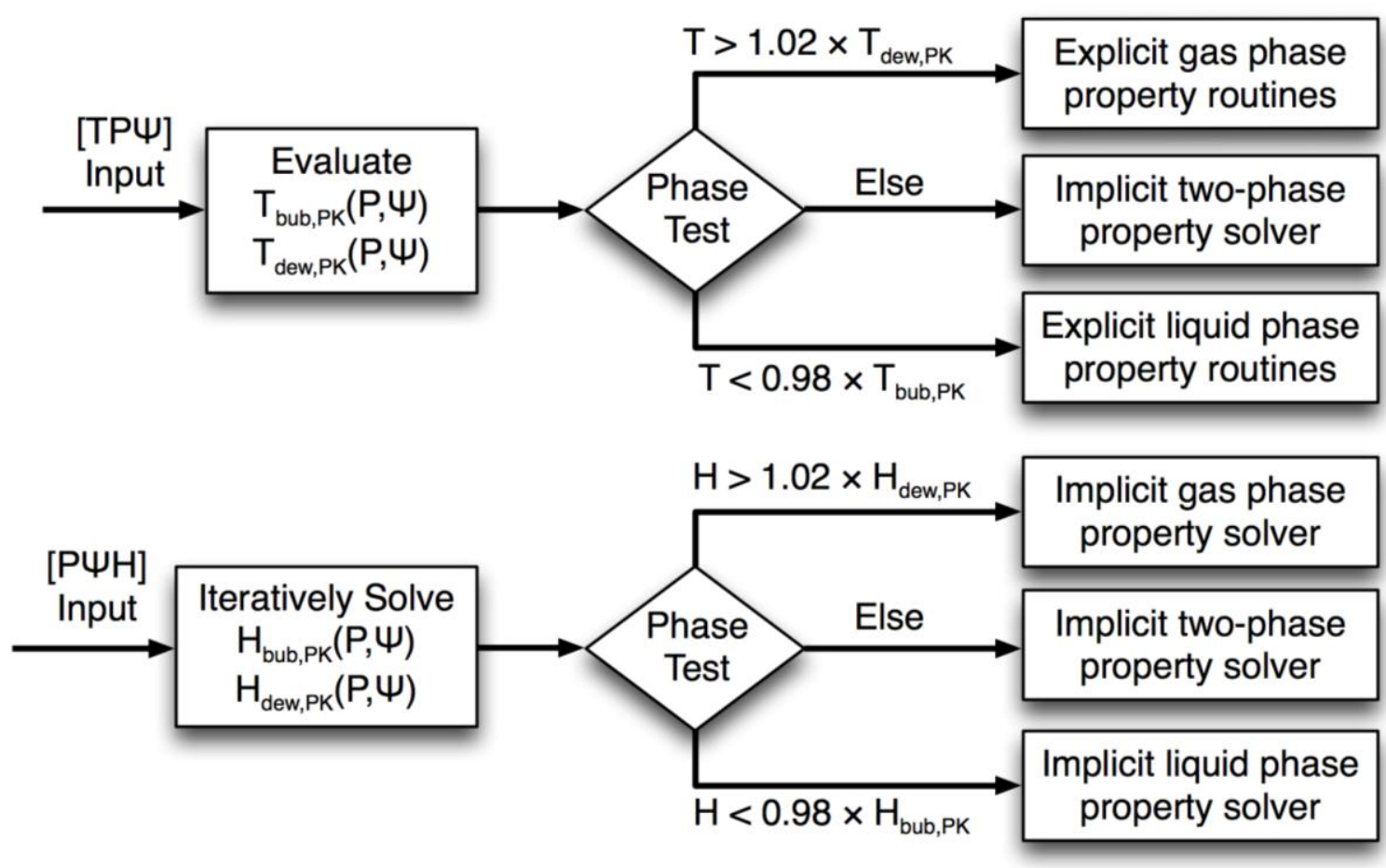

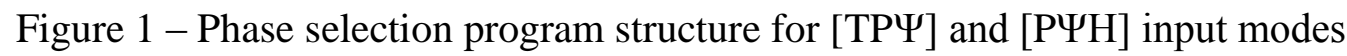

phase state points are not incorrectly classified as single-phase for the property ranges employed

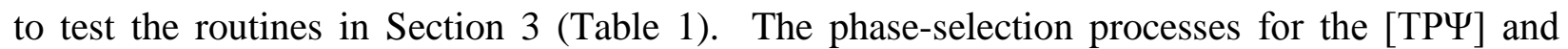
$[\mathrm{P \Psi H}]$ modes are presented schematically in Figure 1 to demonstrate this portion of the property evaluation algorithm.

If an input state point lies within the approximate 2-phase envelope, iterative solution of the equilibrium conditions is necessary. First, the appropriate property-data tree is searched to identify the closest known state point to use as an initial guess. If the retrieved state point is significantly different from the input triple, an alternate initial guess is developed based on the approximate dew and bubble points obtained from the saturation correlations. The input triple 


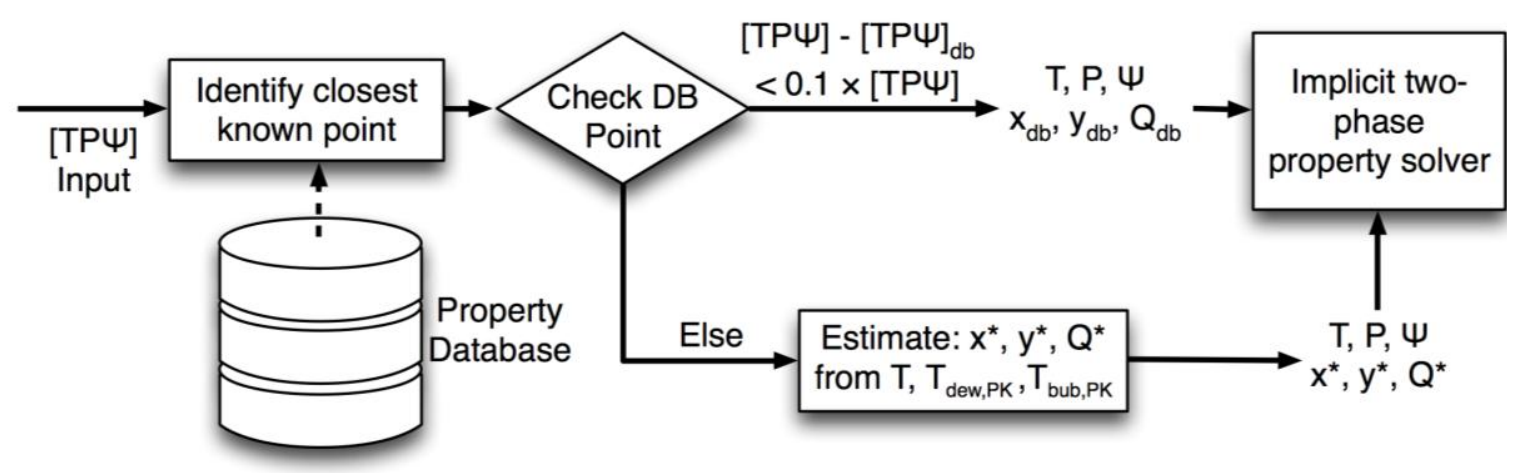

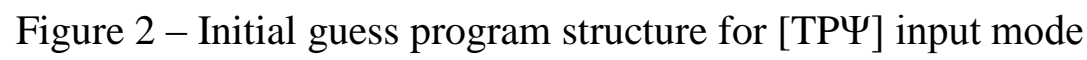

and initial guess are then passed to an iterative solver specific to the input mode.The iterative solvers evaluate equilibrium conditions using tuned, dynamically relaxed and limited, Newtonmethod based approaches. Detailed descriptions of these algorithms are provided in Appendix

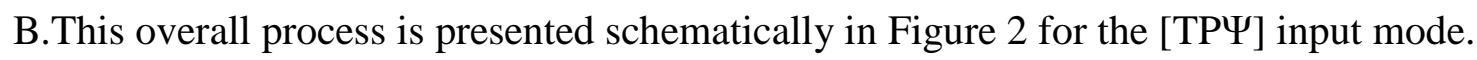

Once the iterative solution is completed, the remaining thermodynamic properties are evaluated explicitly. If an evaluated state point is found to lie in the two-phase region and more than $2-3$ iterations are required for solution, it is added to the property database to improve future initial guesses. The specific threshold iteration count for updating the database was tuned for each solver mode in this study, and the optimal values may vary for future applications depending on the runtime platform and use pattern. The overall structure of the ammonia-water mixture property program is summarized in Figure3.

\subsection{Software implementation}

The ammonia-water mixture property routines developed in this investigation are implemented in the $\mathrm{C}$ programming language, permitting integration with scientific libraries and 
applications written in $\mathrm{C}$ and $\mathrm{C}++$. A default property tablecontaining 1,500 two-phase property points between $10 \mathrm{kPa}$ and $5 \mathrm{MPa}$ is included to seed the property database during program initialization. The property routines are intended for use for $230 \leq T \leq 500 \mathrm{~K}$ and $20 \leq P \leq 5000$ $\mathrm{kPa}$ - the proposed range of validity of the underlying EOS (Ziegler and Trepp, 1984).Additionally, a modified version of the program is implementedas aMATLAB ${ }^{\circledR}$ executable (MEX)function, enabling access to the property routines in the MATLAB ${ }^{\circledR}$ and Simulink ${ }^{\circledR}$ environments. 
Table 1 - Ranges of property sets employed for analyzing performance of ammonia-water property routines

\begin{tabular}{|c|c|c|c|}
\hline \multirow{2}{*}{$\begin{array}{l}\begin{array}{l}\text { Input } \\
\text { mode }\end{array} \\
\text { TP }\end{array}$} & \multicolumn{3}{|c|}{ Input set range } \\
\hline & $T \in[260 \mathrm{~K}, 450 \mathrm{~K}]$ & $P \in[100 \mathrm{kPa}, 5,000 \mathrm{kPa}]$ & $\Psi \in[0,1]$ \\
\hline TPQ & $T \in[265 \mathrm{~K}, 420 \mathrm{~K}]$ & $P \in[100 \mathrm{kPa}, 2,000 \mathrm{kPa}]$ & $Q \in[0,1]$ \\
\hline $\mathrm{T \Psi V}$ & $T \in[265 \mathrm{~K}, 420 \mathrm{~K}]$ & $\Psi \in[0,1]$ & $v \in\left[0.0012 \mathrm{~m}^{3}, 1 \mathrm{~m}^{3}\right]$ \\
\hline 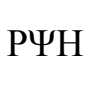 & $P \in[100 \mathrm{kPa}, 5,000 \mathrm{kPa}]$ & $\Psi \in[0,1]$ & $h \in\left[-250 \mathrm{~kJ} \mathrm{~kg}^{-1}, 2,500 \mathrm{~kJ} \mathrm{~kg}^{-1}\right]$ \\
\hline $\mathrm{P \Psi Q}$ & $P \in[100 \mathrm{kPa}, 5,000 \mathrm{kPa}]$ & $\Psi \in[0,1]$ & $Q \in[0,1]$ \\
\hline$\Psi V U$ & $\Psi \in[0,1]$ & $v \in\left[0.01 \mathrm{~m}^{3}, 1 \mathrm{~m}^{3}\right]$ & $u \in\left[200 \mathrm{~kJ} \mathrm{~kg}^{-1}, 2,000 \mathrm{~kJ} \mathrm{~kg}^{-1}\right]$ \\
\hline
\end{tabular}

\section{Performance and Assessment}

\subsection{Performance of ammonia-water property routines}

The performance of the six ammonia-water property routines developed in this study is investigated on a personal computer with a $2.2 \mathrm{GHz}$ CPU. Random input sets of 2,000 property points in the expected operating ranges (Table1) for absorption refrigerators and heat pumps are generated for each property mode.

Average property evaluation times for the 6 input modes are estimated by timing the program execution for 10 runs of each 2,000 point input set (Table 2). The program is reinitialized after each input set evaluation; therefore, the reported average state point evaluation times include a small fraction $(0.05 \%)$ of the program initialization and termination overhead. Thus, users should expect relatively longer individual property evaluation times for smaller input sets.

The [TPЧ] input mode is found to yield the shortest average state point evaluation time (49 $\mu \mathrm{s})$. This rapid property evaluation is due to the fact that many input points in the range defined 
Table 2 - Average individual property point evaluation times for each input mode

\begin{tabular}{|c|c|}
\hline $\begin{array}{l}\text { Input } \\
\text { mode }\end{array}$ & $\begin{array}{l}\text { Average state point } \\
\text { evaluation time }(\mu \mathrm{s})\end{array}$ \\
\hline 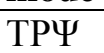 & 49 \\
\hline TPQ & 127 \\
\hline TYV & 492 \\
\hline $\mathrm{P \Psi H}$ & 389 \\
\hline $\mathrm{P \Psi Q}$ & 931 \\
\hline TVU & 768 \\
\hline
\end{tabular}

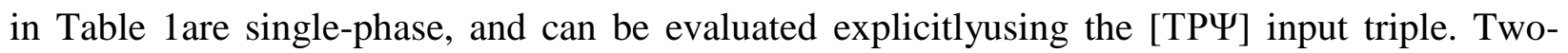

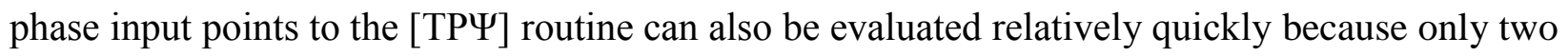
parameters $(x, y)$ are solved implicitly. The average [TPQ] state point evaluation takes about 2.5 times longer, which is unsurprising as all inputs require iterative solution of $x$ and $y$. Evaluation of $[\mathrm{T \Psi V}]$ and $[\mathrm{P \Psi H}]$ triples is significantly slower, requiring about 10and 8times as long as

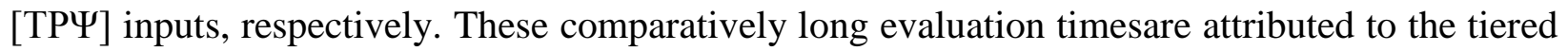
iterative solution required for $x$ and $y$, and $P$ or $T$ for two-phase points, and the iterative solution

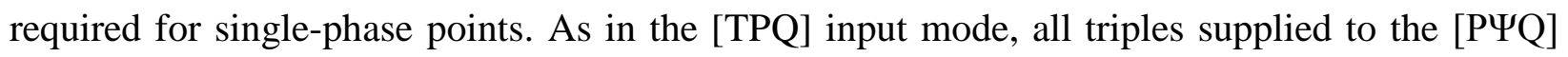
routine require two-phase iterative solution; therefore, the average evaluation time is about $140 \%$ longer than for the $[\mathrm{P \Psi H}]$ mode.A long average state point evaluation time $(768 \mu \mathrm{s})$ is measured for [ $\Psi \mathrm{VU}]$ property routine because iterative solution of two $(T, P)$ or $4(T, P, x, y)$ properties is required for single- and two-phase inputs, respectively.

The property evaluation routines developed in this study are profiled using the GNU gprof tool (Stallman and Fenlason, 2009) to estimate the relative computational costs of different program components for each input mode (Figure4). The profiling study was conducted using the same 2,000 point randomly generated input sets employed in the initial performance study, 

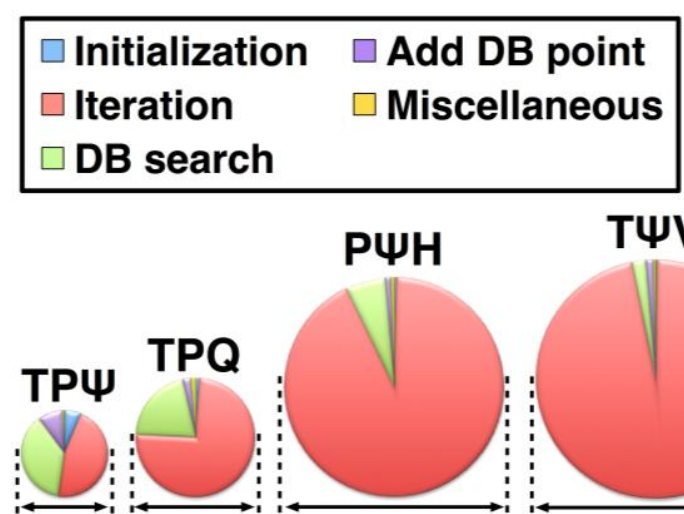

$1.3 \mathrm{~s} \quad 2.5 \mathrm{~s}$

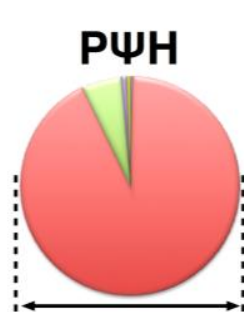

$8.4 \mathrm{~s}$
TUV

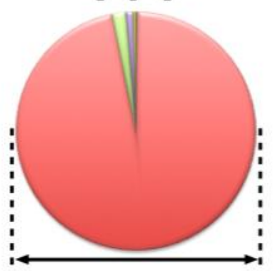

$10.0 \mathrm{~s}$

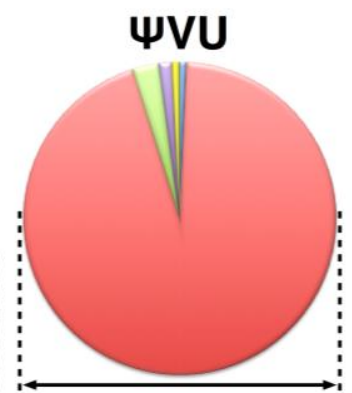

$16.8 \mathrm{~s}$
$\mathbf{P \Psi Q}$

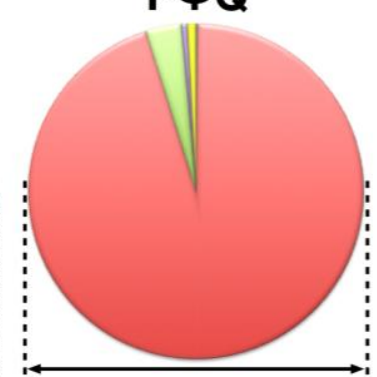

$19.3 \mathrm{~s}$

Figure 4 - Relative computational costs of property routine components and total run time for 100 executions of 2,000 random property point evaluations

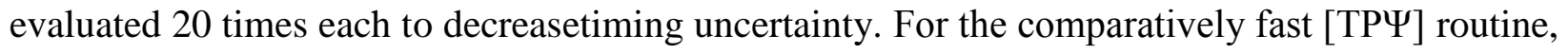
program overhead for initialization and termination, database searches, and database updates account for approximately $54 \%$ of the total program run time. The $6.3 \%$ of runtime spent on program initialization and termination should decrease to a negligible amount for very large

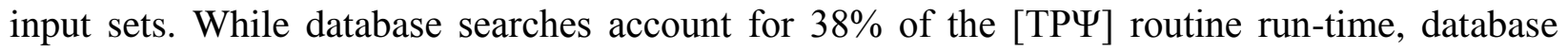
updates require only $9-10 \%$ as only two-phase property points that require more than twoiterations for evaluation are stored. A greater fraction of the [TPQ] routine run-time (75\%) is spent on iteration and single-phase property evaluations because all inputs require computationally expensive two-phase implicit solution.Over $90 \%$ of program execution time is spent during iteration for the remaining property evaluation modes, which require implicit

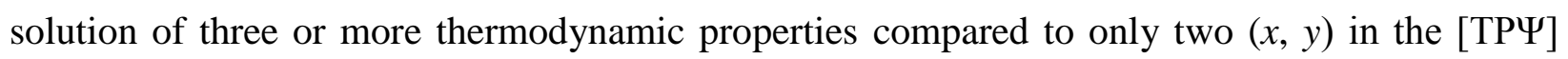
and [TPQ] modes. 


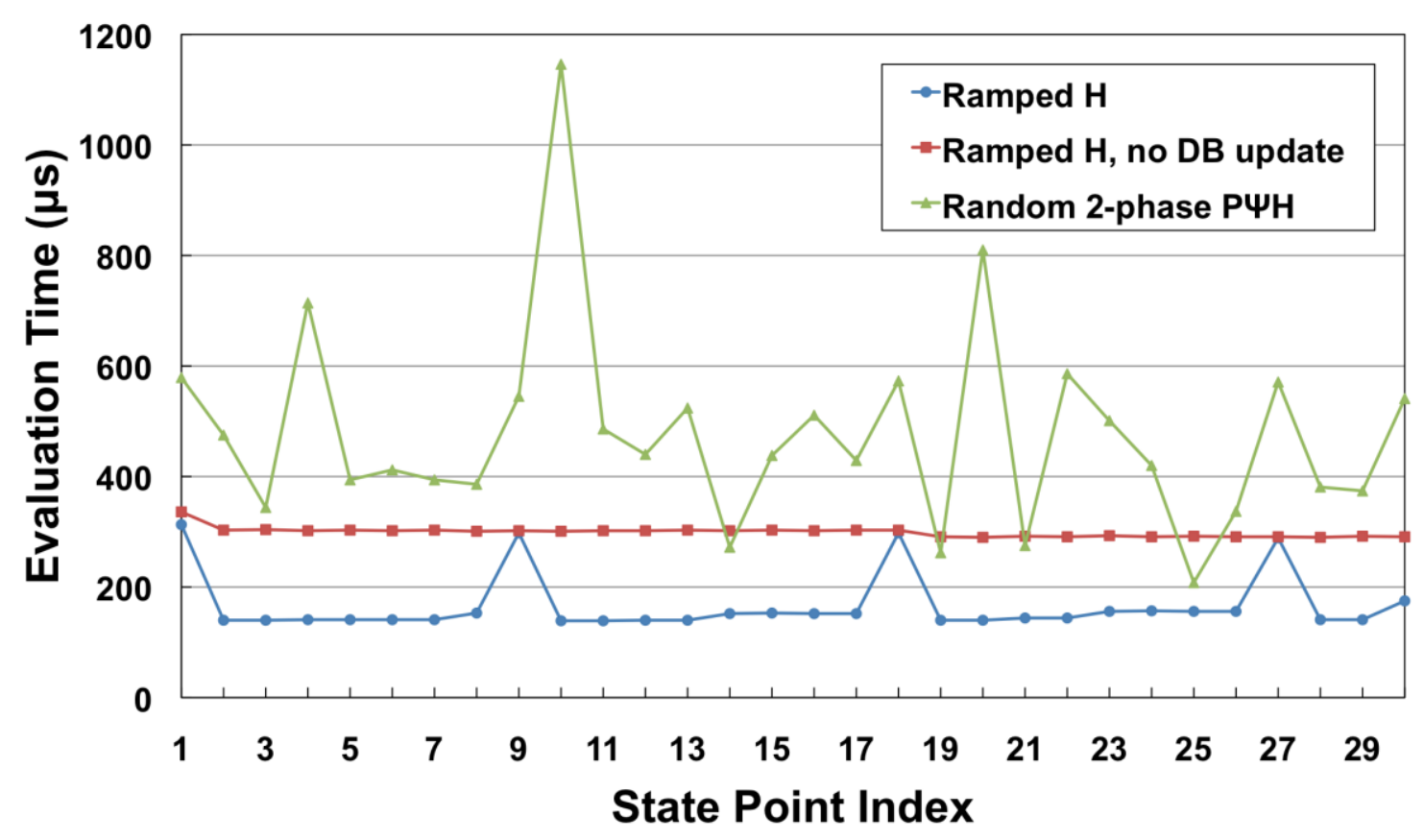

Figure 5 - Comparison of ramped property point evaluation times with and without run-time database updates to random property point evaluation times

\subsection{Effects ofrun-time property databaseonprogram performance}

This study introduces the use of a run-time database of previously evaluated two-phase state points for use as initial guesses for future property points. The performance improvement achieved with this technique is demonstrated through a sample study in which the properties of an ammonia-water mixture $(P=600 \mathrm{kPa}, \psi=0.5)$ are evaluated sequentially at 30 uniformlyspaced points with enthalpy ramped from 500 to $600 \mathrm{~kJ} \mathrm{~kg}^{-1}$. Similar input sets could arise in segmented and/or transient heat exchanger models or in parametric absorption studies at varying operating conditions. These state points are evaluated using the $[\mathrm{P} \Psi \mathrm{H}]$ routine described in section B.4 and with a modified code that does not update the run-time property database.

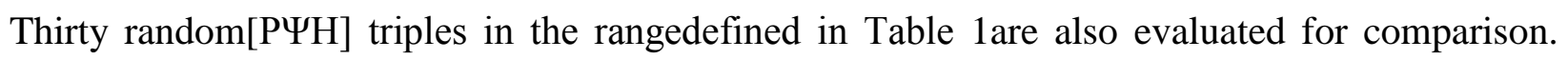
Each state point evaluation in this comparison is timed, and executed 100 times to 
decreasemeasurement uncertainty. A summary of average evaluation times is presented in Figure5.

Inspection of Figure5reveals that evaluation of the initial state point $\left(h=500 \mathrm{~kJ} \mathrm{~kg}^{-1}\right)$ took $313 \mu \mathrm{s}$, and the point was added to the database asmore than threeiterations were required. This property point served as an accurate initial guess for the following seven points (up to $h=$ $524 \mathrm{~kJ} \mathrm{~kg}^{-1}$ ), enabling solutions in $140-150 \mu \mathrm{s}$. The following point (9) required more iterations and a longer solution time $(298 \mu \mathrm{s})$, and was thus stored in the database to be used as an initial guess for points $10-17$. This pattern of individual slow property evaluations followed by many rapid evaluations is repeated for the rest of the input set. In contrast, if the database is not updated after computationally expensive property evaluations, every point requires about $300 \mu \mathrm{s}$ for solution. Thus, in this representative example, the use of a run-time database of property points decreaseaverage property evaluation time by $45 \%$ from $300 \mu$ s to $167 \mu$ s. Note that the advantage of the run-time database is only realized when many relatively close property points are evaluated in a study. The third curve in Figure5demonstrates the relatively long evaluation times obtained from a random input set, even when database updates are performed.

Similar performance gains could also be obtained by allowing the user to input an initial guess for the state point - perhaps the value at a neighboring segment in a discretized model, or from the previous time step in a transient model. However, such an approach may prove tedious for the end user, who would have to track extra quantities. For example, a user may be interested in the quality of a fluid volume at the state point $(\psi, v, u)$, but a full initial guess of the property point would include $T, P, x$, and $y$. In a large study, tracking multiple extra thermodynamic properties for each segment or volume may be infeasible due to memory limitations. Furthermore, if properties change significantly between subsequent time steps or neighboring 
Table 3 - Average evaluation times for single- and two-phase property points

\begin{tabular}{|c|c|c|}
\hline \multirow{2}{*}{$\begin{array}{l}\text { Input } \\
\text { mode }\end{array}$} & \multicolumn{2}{|c|}{ Average state point evaluation time $(\mu \mathrm{s})$} \\
\hline & Single-phase & Two-phase \\
\hline 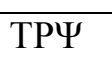 & 18 & 88 \\
\hline 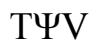 & 429 & 520 \\
\hline 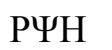 & 142 & 363 \\
\hline$\Psi V U$ & 775 & 770 \\
\hline
\end{tabular}

segments in a discretized model, the run-time property database may be able to identify more suitable initial guess points than would be supplied by a user who is focused on other elements of a simulation.

\subsection{Effects of implemented saturation correlations on program performance}

If ammonia-water is known to be single-phase at a given state point, only $T, P$, and $\psi$ must be known for explicit evaluation of the remaining properties. By comparing input property points to approximate saturation correlations (Pátek and Klomfar, 1995), iterative solution can be simplified or avoided for points sufficiently outside the two-phase region. Sets of 2,000 randomly generated single- and two-phase property points $(T \in[260 \mathrm{~K}, 450 \mathrm{~K}]$,

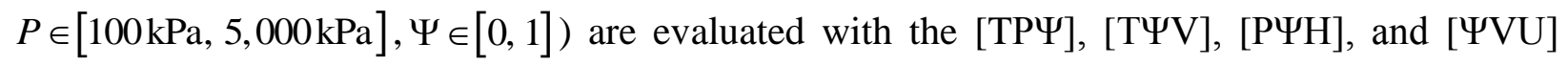
property routines. Note that the $[\mathrm{TPQ}]$ and $[\mathrm{P \Psi Q}]$ property evaluation modes are not considered here as they require two-phase iteration for all input sets. Average single- and two-phase property execution times are summarized in Table 3.

Inspection of Table 3 reveals that by employing saturation correlations, single-phase property points can be evaluated about 5and 2.5 times faster than two-phase property points with the $[T P \Psi]$ and $[\mathrm{P \Psi H}]$ property routines, respectively.Due to the relatively low sensitivity of liquid 
specific volume to $T$ and $\psi$, it is difficult to distinguish single-phase liquid inputs from two-phase inputs to the $[\mathrm{T \Psi V}]$ property routine. Thus, the evaluation of single-phase fluid inputs is only slightly faster $(17 \%)$ than two-phase inputs, because two-phase iteration is often initiated for such points, and convergence behavior may be poor for state points significantly sub-cooled below the saturated liquid condition.Similarly, as the saturation limits can only be estimated approximately for [YVU] triples using the correlations of Pátek and Klomfar (1995), some twophase iteration may be performed on single-phase property points. Thus, the average [ $\Psi \mathrm{VU}]$ mode single- and two-phase state point evaluation times are nearly equal.

\subsection{Comparison of developed property routines to existing software packages}

An analysis was conducted to compare the performance of the proposed ammonia-water thermodynamic routines with those of existing software packages, namely $\mathrm{NH} 3 \mathrm{H} 2 \mathrm{O}$ in EES (Klein, 2014) and REFPROP 9 (Lemmon et al., 2010). The property routines developed in this study are based on the empirical EOS formulation of Ziegler and Trepp (1984), while NH3H2O employs the updated formulation by Ibrahim and Klein (1993) and REFPROP 9 incorporates the first principles based EOS of Tillner-Roth and Friend (1998a). Thus, the reader is advised that the advantage of faster property evaluation times achieved in this study may be offset by the limited range of applicability of the underlying EOS (known to be valid only up to $5 \mathrm{MPa}$ ).

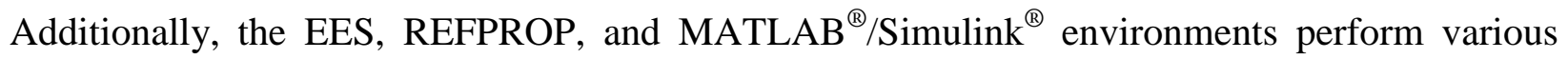
background and ancillary tasks during computation; therefore, the reported state point evaluation times may include different degrees of program overhead not intrinsic to the studied property routines. The 2,000 state point $(T, P, \psi)$ and $(P, \psi, h)$ sets considered in Section 3.1 were evaluated with the developed standalone and MATLAB ${ }^{\circledR}$ executable property routines, $\mathrm{NH} 3 \mathrm{H} 2 \mathrm{O}$, and REFPROP 9 on a PC with a $2.2 \mathrm{GHz}$ CPU (Table 4). Note that REFPROP 9 failed to 
Table 4 - Comparison of average property evaluation times between routines developed in this study and existing software packages

\begin{tabular}{|c|c|c|}
\hline \multirow[b]{2}{*}{ Software tool } & \multicolumn{2}{|c|}{ Average state point evaluation time (ms) } \\
\hline & {$[\mathbf{T P \Psi}]$} & {$[\mathbf{P \Psi H}]$} \\
\hline Proposed standalone program & 0.05 & 0.39 \\
\hline Proposed MATLAB routines & 0.25 & 1.09 \\
\hline NH3H2O in EES (Klein, 2014) & 7.45 & 9.35 \\
\hline REFPROP 9 (Lemmon et al., 2010) & *49.72 & *** $1,252.04$ \\
\hline
\end{tabular}

converge for 6 of the input $(T, P, \psi)$ triples. Also, due to the substantial program run time, only the first $100(P, \psi, h)$ triples were evaluated in REFPROP 9, and convergence was not achieved for 8 of these state points. As mentioned earlier, it is unclear if these stability limitations are intrinsic to the Tillner-Roth and Friend (1998a)property formulation, or the REFPROP implementation thereof.

Inspection of Table 4 reveals that the MATLAB ${ }^{\circledR}$ implementation of the developed property routines runs significantly slower than the standalone program. The increased execution time is partially due to additional program overhead and slower memory manipulation routines in the MATLAB ${ }^{\circledR}$ environment. By default, the MATLAB ${ }^{\circledR}$ implementation performs run-time database updates for all 6 program modes. If the implementation is modified to only update the $(T, P, \psi)$ and $(P, \psi, h)$ indexed property trees, the average $[\mathrm{TP} \Psi]$ and $[\mathrm{P} \Psi \mathrm{H}]$ evaluation times decrease from 250 and $1,090 \mu \mathrm{s}$ to 160 and $1,060 \mu \mathrm{s}$, respectively. The $\mathrm{NH} 3 \mathrm{H} 2 \mathrm{O}$ routine was studied using the Parametric Table tool in EES, and was found to perform state point evaluations 149 and 24 times slower than the developed standalone program for the $[\mathrm{TP} \Psi]$ and $[\mathrm{P \Psi H}]$ modes, respectively. However, experience with the EES environment indicates that a large portionof the 
measured execution time is likely occupied by program overhead, and not the $\mathrm{NH} 3 \mathrm{H} 2 \mathrm{O}$ routine itself. This performance study also found that the developed standalone program evaluates state points for $(T, P, \psi)$ triples about 940 times faster than REFPROP 9 without encountering convergence failures. An even greater speed up was found by comparing the $(P, \psi, h)$ performance of the two programs. However, a large fraction of the REFPROP 9 evaluation time may have been expended on state points for which convergence was not obtained. The difference in $(P, \psi, h)$ evaluation times may be comparable to that for $(T, P, \psi)$ inputs if non-convergent points are ignored. Overall, the routines developed in this study achieve dramatic speed-ups in property evaluation times compared to existing software. However, the authors caution that the compared tools comprise fundamentally different software environments and implement different formulations of the ammonia-water mixture properties.

\section{Representative Engineering Application and Assessment}

\subsection{Ammonia-water absorber model}

Many detailed steady-state models of absorption system heat and mass exchangers have been reported in the literature.However, transient component analyses are critical for understanding system performance during start-up/shut-down events and varying operating conditions(Pierre, 1959). Additionally, transient simulations can inform the development of device controls strategies (Goyal et al., 2015).Such studies can be extremely computationally intensive, requiring millions of state-point evaluations instead of hundreds, as in most steady state analyses. Mixture property evaluations account for a major portion of the computational costs in these cases because the remaining governing equations (e.g., mass and energy balances) can be represented as simple, well-conditioned, systems of ordinary differential equations. 


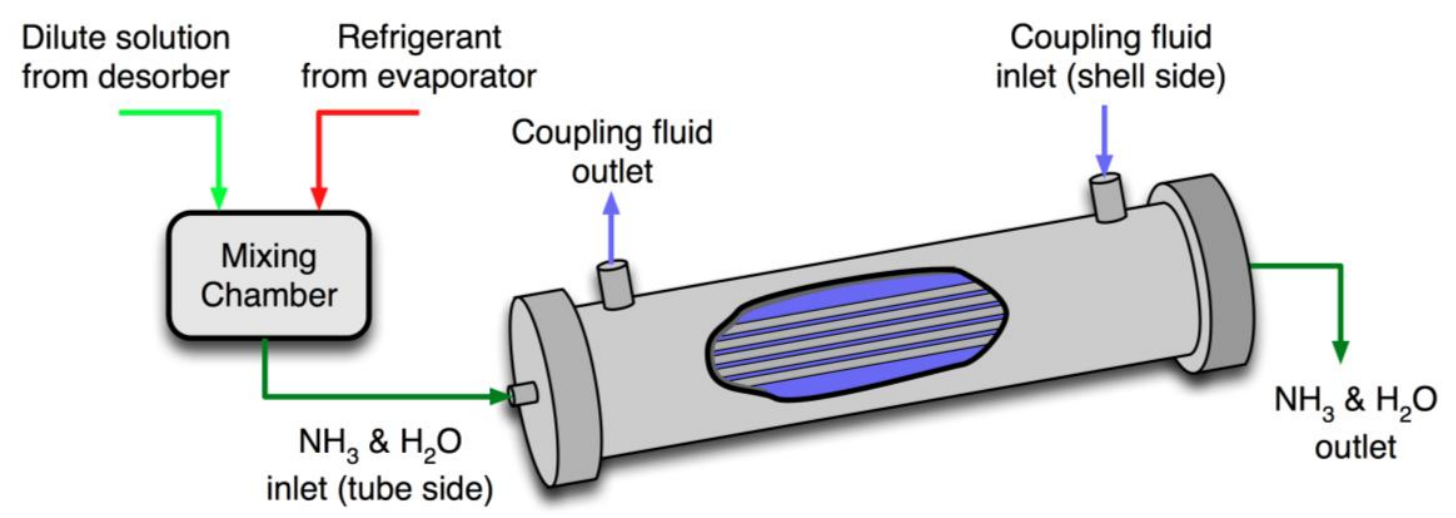

Figure 6 - Schematic of representative absorber under investigation

The proposed ammonia-water property routines are thus incorporated into a transient segmented model of a representative absorption chiller absorber to evaluate their performance in a computationally expensive engineering application. The absorber investigated here is a liquidcooled counter-flow heat exchanger with refrigerant and solution premixed upstream of the ammonia-water inlet (Figure6).

The model developed in this study divides the heat exchanger into three $1 \mathrm{D}$ sub-domains for the cooling coupling fluid, internal dividing wall, and ammonia-water two-phase mixture (Figure7). Operational parameters and material properties for this absorber model are summarized in Table 5.

The cooling coupling fluid is assumed to be single-phase and incompressible; therefore, the mass conservation equation for each segment, $\mathrm{j}$, of the coupling fluid domain reduces to: $\dot{m}_{\mathrm{e}, \mathrm{cf}, \mathrm{j}}=\dot{m}_{\mathrm{i}, \mathrm{cf}, \mathrm{j}}=32 \mathrm{~g} \mathrm{~s}^{-1}$. The segmental energy conservation equation (Equation1) employs firstorder upwinding to determine outlet enthalpy, and a uniform segmental temperature profile assumption to estimate heat transfer with the neighboring dividing wall segment. Uniform 


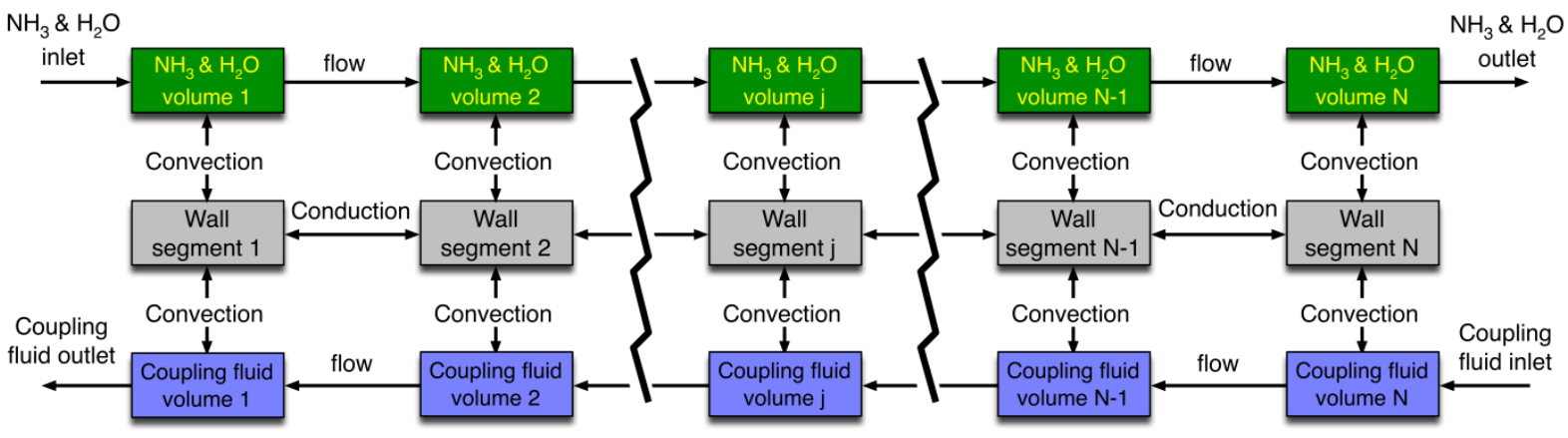

Figure 7 - Discretization scheme for representative absorber under investigation

coupling fluid side heat transfer conductance values $\left((U A)_{\mathrm{cf-w}, \mathrm{j}}=30 \mathrm{~W} \mathrm{~K}^{-1}\right)$ are employed in each segment. The coupling fluid is assumed to have a constant specific heat; therefore, the enthalpy and temperature are related by: $h_{\mathrm{cf}}=c_{\mathrm{p}, \mathrm{cf}}\left(T_{\mathrm{cf}}-T_{0}\right)$ where $c_{\mathrm{p}, \mathrm{cf}}=2.0 \mathrm{~kJ} \mathrm{~kg}^{-1} \mathrm{~K}^{-1}$ and $T_{0}=0^{\circ} \mathrm{C}$. All coupling fluid segments have equal volumes of $V_{\mathrm{cf}, \mathrm{j}}=10^{-4} \mathrm{~m}^{3}$, densities of $\rho_{\mathrm{cf}, \mathrm{j}}=900 \mathrm{~kg} \mathrm{~m}^{-3}$, and thus, fluid masses of $m_{\mathrm{cf}, \mathrm{j}}=0.09 \mathrm{~kg}$. Thus, from left to right, the energy balance equation (Equation1) accounts for energy storage in the control volume, inlet and outlet fluid enthalpy, and heat transfer with the adjacent wall segment.

$$
\frac{d H_{\mathrm{cf}, \mathrm{k}}}{d t}=\dot{m}_{\mathrm{i}, \mathrm{cf}, \mathrm{j}} h_{\mathrm{i}, \mathrm{cf}, \mathrm{j}}-\dot{m}_{\mathrm{e}, \mathrm{ef}, \mathrm{j}} h_{\mathrm{e}, \mathrm{ff}, \mathrm{j}}+(U A)_{\mathrm{cf}-\mathrm{w}, \mathrm{j}}\left(T_{\mathrm{w}, \mathrm{j}}-T_{\mathrm{cf}, \mathrm{j}}\right)
$$

Each segment of the internal dividing wall exchanges heat with its neighboring segments through conduction, and adjacent coupling fluid and ammonia-water volumes through convection. The dividing wall is assumed to have constant material properties $\left(k_{\mathrm{w}}=14 \mathrm{~W} \mathrm{~m}^{-1} \mathrm{~K}^{-1}\right.$ , $\left.c_{\mathrm{p}, \mathrm{w}}=0.51 \mathrm{~kJ} \mathrm{~kg}^{-1} \mathrm{~K}^{-1}\right)$, similar geometry in each segment $\left(A_{\mathrm{w}, \mathrm{j}}=0.01 \mathrm{~m}^{2}, m_{\mathrm{w}, \mathrm{j}}=0.2 \mathrm{~kg}\right)$, and uniform spacing between adjacent segments $\left(l_{\mathrm{w}, \mathrm{j}}=0.05 \mathrm{~m}\right)$. Heat transfer with the coupling fluid 
and ammonia-water volumes adjacent to each wall segment are evaluated assuming uniform segmental coupling fluid and solution side heat transfer conductance values: $(U A)_{\mathrm{cf}-\mathrm{w}, \mathrm{j}}=30 \mathrm{~W} \mathrm{~K}^{-1}$ and $(U A)_{a \mathrm{w}-\mathrm{w}, \mathrm{j}}=100 \mathrm{WK}^{-1}$, respectively. As in the coupling-fluid model, uniform segmental temperature profiles are assumed in each wall segment for heat transfer computations. Thus, the governing energy conservation equation for wall segment $\mathrm{j}$ is: 
Table 5 - Ammonia-water absorber fluid properties and configuration parameters

\begin{tabular}{lccl}
\hline \multicolumn{1}{c}{ Description } & Parameter & Value & \multicolumn{1}{c}{ Units } \\
\hline Coupling fluid properties & & \\
Specific heat & $c_{\mathrm{p}, \mathrm{cf}}$ & 2.0 & $\mathrm{~kJ} \mathrm{~kg}^{-1} \mathrm{~K}^{-1}$ \\
Density & $\rho_{\mathrm{cf}}$ & 900 & $\mathrm{~kg} \mathrm{~m}^{3}$ \\
Segment volume & $V_{\mathrm{cf}, \mathrm{j}}$ & $10^{-4}$ & $\mathrm{~m}^{3}$ \\
Segment mass & $m_{\mathrm{cf}, \mathrm{j}}$ & 0.09 & $\mathrm{~kg}$ \\
Flow rate & $\dot{m}_{\mathrm{cf}}$ & 32 & $\mathrm{~g} \mathrm{~s}^{-1}$ \\
\hline
\end{tabular}

Internal wall properties

\begin{tabular}{lcrl} 
Specific heat & $c_{\mathrm{w}}$ & 0.51 & $\mathrm{~kJ} \mathrm{~kg}^{-1} \mathrm{~K}^{-1}$ \\
Thermal conductivity & $k_{\mathrm{w}}$ & 14 & $\mathrm{~W} \mathrm{~m}^{-1} \mathrm{~K}^{-1}$ \\
Cross-section area & $A_{\mathrm{w}, \mathrm{j}}$ & 0.01 & $\mathrm{~m}^{2}$ \\
Segment length & $l_{\mathrm{w}, \mathrm{j}}$ & 0.05 & $\mathrm{~m}$ \\
Segment mass & $m_{\mathrm{w}, \mathrm{j}}$ & 0.2 & $\mathrm{~kg}$ \\
\hline & Ammonia-water fluid properties & \\
Flow rate & $\dot{m}_{\mathrm{aw}}$ & $\sim 4$ & $\mathrm{~g} \mathrm{~s}^{-1}$ \\
Ammonia concentration & $\psi_{\mathrm{aw}}$ & $\sim 0.475$ & - \\
\hline
\end{tabular}

Segmental heat transfer conductance values

Coupling fluid to wall

$(U A)_{\text {cf-w. }}$

30

$\mathrm{W} \mathrm{K}^{-1}$

Ammonia-water to wall

$(U A)_{\mathrm{aw}-\mathrm{w}, \mathrm{j}}$

100

$\mathrm{W} \mathrm{K}^{-1}$

$$
\frac{d T_{\mathrm{w}, \mathrm{j}}}{d t}=\left\{\begin{array}{l}
\frac{k_{\mathrm{w}} A_{\mathrm{w}, \mathrm{j}}}{l_{\mathrm{w}, \mathrm{j}}}\left(T_{\mathrm{w}, \mathrm{j}-1}-T_{\mathrm{w}, \mathrm{j}}\right)+\frac{k_{\mathrm{w}} A_{\mathrm{w}, \mathrm{j}}}{l_{\mathrm{w}, \mathrm{j}}}\left(T_{\mathrm{w}, \mathrm{j}+1}-T_{\mathrm{w}, \mathrm{j}}\right)+ \\
(U A)_{\mathrm{cf}-\mathrm{w}, \mathrm{j}}\left(T_{\mathrm{cf}, \mathrm{j}}-T_{\mathrm{w}, \mathrm{j}}\right)+(U A)_{\mathrm{aw}-\mathrm{w}, \mathrm{j}}\left(T_{\mathrm{aw}, \mathrm{j}}-T_{\mathrm{w}, \mathrm{j}}\right)
\end{array}\right\} / m_{\mathrm{w}, \mathrm{j}} c_{\mathrm{p}, \mathrm{w}}
$$

The ammonia-water mixture flowing into the absorber is assumed to be a mixture of the dilute solution flowing out of the absorber (saturated liquid, $x_{\text {sol }}=0.3, P_{\text {sol }}=500 \mathrm{kPa}$, and $\dot{m}_{\text {sol }}=3 \mathrm{~g} \mathrm{~s}^{-1}$ ) and refrigerant vapor from the evaporator (saturated vapor, $y_{\text {ref }}=0.999, P_{\text {ref }}=500 \mathrm{kPa}$, at a time varying flow rate of $\dot{m}_{\text {ref }}=0.96-1.04 \mathrm{~g} \mathrm{~s}^{-1}$ ). As the two-phase ammonia-water mixture flowing 
through the absorber has substantial variations in density, the exact 1-D forms of the continuity and momentum balance equations are quite complicated and require coupled inter-phase slip models for closure. For this absorber model, which is only intended to demonstrate the use of the property routines in practical engineering calculations, mass and energy storage are neglected in the ammonia-water fluid volumes to simplify the governing equations. Thus, the mass and species conservation equations for each ammonia-water fluid volume, $\mathrm{j}$, reduce to: $\dot{m}_{\mathrm{i}, \mathrm{j}}=\dot{m}_{\mathrm{e}, \mathrm{j}} \approx 4 \mathrm{~g} \mathrm{~s}^{-1}$ and $\psi_{\mathrm{i}, \mathrm{j}}=\psi_{\mathrm{e}, \mathrm{j}} \approx 0.475$. The fluid volume energy balance assumes that both phases are in thermal equilibrium at the saturation conditions and employs first-order upwinding to determine outlet enthalpy. The rate of heat transfer with the wall is estimated using a uniform temperature profile in each segment of the discretized system. Thus, from left to right, Equation3yields the outlet fluid enthalpy from the sum of the inlet fluid enthalpy and the specific heat transfer rate with the adjacent wall segment.

$$
h_{\mathrm{aw}, \mathrm{e}, \mathrm{j}}=h_{\mathrm{aw}, \mathrm{i}, \mathrm{j}}+\frac{(U A)_{\mathrm{aw}-\mathrm{w}, \mathrm{j}}\left(T_{\mathrm{w}, \mathrm{j}}-T_{\mathrm{aw}, \mathrm{j}}\right)}{\dot{m}_{\mathrm{aw}, \mathrm{e}, \mathrm{j}}}
$$

The transient ammonia-water absorber model is implemented in Simulink ${ }^{\circledR}$ with five segments in each sub-domain. The ammonia-water properties routines developed in this study

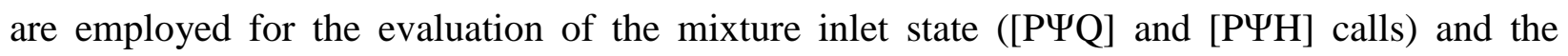

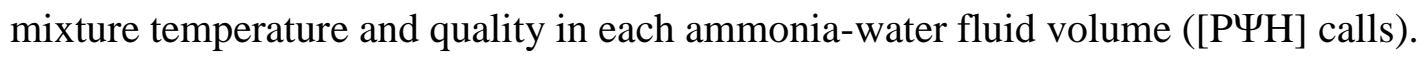

\subsection{Analysis of transient absorber model}

The ammonia-water absorber model is configured to simulate an experimental airconditioning system with a cooling duty of approximately $1.3 \mathrm{~kW}$. Saturated dilute solution $(x=$ 0.3 ) enters the mixing chamber at $500 \mathrm{kPa}$ with a flow rate of $3 \mathrm{~g} \mathrm{~s}^{-1}$. To simulate the fluctuating refrigerant flow rate often observed in experimental absorption refrigeration systems, the 
concentrated refrigerant $(y=0.999)$ enters the mixing chamber at $500 \mathrm{kPa}$ with a flow rate prescribed by Equation4.

$$
\dot{m}_{v, i n}=\left(1 \mathrm{~g} \mathrm{~s}^{-1}\right)+\left(0.04 \mathrm{~g} \mathrm{~s}^{-1}\right) \sin \left[2 \pi\left(0.5 \mathrm{~s}^{-1}\right) \mathrm{t}\right]
$$

Cooling coupling fluid flows through the absorber at $32 \mathrm{~g} \mathrm{~s}^{-1}$. To simulate start-up of the chillersystem, the coupling fluid inlet temperature is initially set to $35^{\circ} \mathrm{C}$, and is ramped down linearly to $20^{\circ} \mathrm{C}$ from simulation times $25 \mathrm{~s}$ to $70 \mathrm{~s}$. The five segment absorber model is evaluated for 100 simulation seconds in Simulink ${ }^{\circledR}$ on a $2.2 \mathrm{GHz}$ PC and resulting inlet and outlet ammonia-water mixture qualities and coupling-fluid temperatures are presented in Figure8.

Inspection of Figure 8 reveals that the simulated ammonia-water absorber experiences initial fluctuations for the first 25 seconds as fluid volume and wall segments transition from prescribed initial conditions to cyclic steady state. The average outlet ammonia-water mixture quality decreases rapidly after the coupling fluid inlet temperature begins to decrease at $25 \mathrm{~s}$, until full absorption is achieved at $67 \mathrm{~s}$. The absorber achieves final cyclic steady state conditions by $95 \mathrm{~s}$, at which point the coupling fluid outlet temperature reaches $59.3^{\circ} \mathrm{C}$ and a total heat removal rate of $2.5 \mathrm{~kW}$ is obtained. While the inlet ammonia-water flow quality varies by $3 \%$ during the study, the overall change in mixture inlet temperature is only $0.5^{\circ} \mathrm{C}$. This small change in ammonia-water mixture inlet temperature combined with the damping effect of energy storage and diffusion in the wall sub-domain causes fluctuations in the coupling fluid outlet temperature to only be on the order of $10^{-30} \mathrm{C}$. 


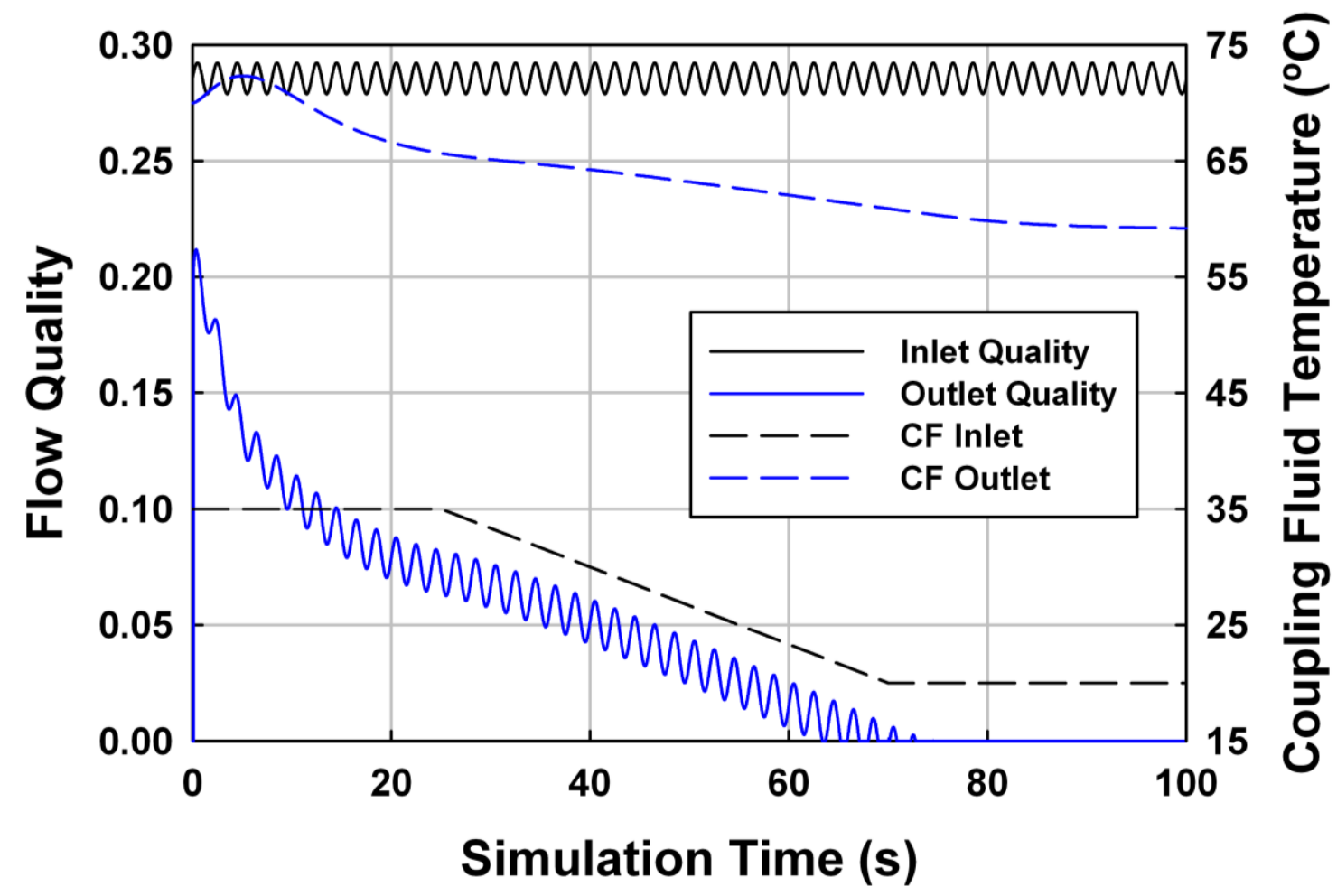

Figure 8 - Ammonia-water mixture qualities and coupling fluid temperatures obtained from the transient absorber model

Due to the small integration steps $(0.01 \mathrm{~s})$ required to correctly track the fluctuating refrigerant vapor flow rate, the $100 \mathrm{~s}$ simulation required 530seconds of processor time. A separate profiling study indicated that $28.3 \%$ of the simulation computation time was spent on 780,391 $[\mathrm{P} \Psi \mathrm{H}]$ and $[\mathrm{P} \Psi \mathrm{Q}]$ ammonia-water property calls, suggesting an average state point execution time of $192 \mu \mathrm{s}$. The Simulink ${ }^{\circledR}$ algebraic loop solver that evaluated the coupled transport equations between the fluid and wall segments accounted for $51.7 \%$ of the simulation runtime. Simulation overhead and other function evaluations accounted for the remaining $20 \%$ of the execution time. Note that the Simulink ${ }^{\circledR}$ profiling tools increased the simulation execution time by a factor of 5.5; therefore, the timing and profiling studies were conducted independently. The versions of the property routines employed here were found to execute slower than the 
standalone program investigated in Sections $3.1-3.4$ due to additional program overhead and slower memory manipulation routines in the MATLAB ${ }^{\circledR}$ and Simulink ${ }^{\circledR}$ environments.

\section{Conclusions}

This study presented the development ofsoftware routines to evaluate the thermodynamic properties of ammonia-water mixtures for use in refrigeration and air-conditioning applications. A number of property formulations were surveyed, and the empirical EOS approach ofZiegler and Trepp (1984) was selected for use in this investigation due to its intrinsic consistency and accuracy in the thermodynamic conditions of interest and potential for high computational speed

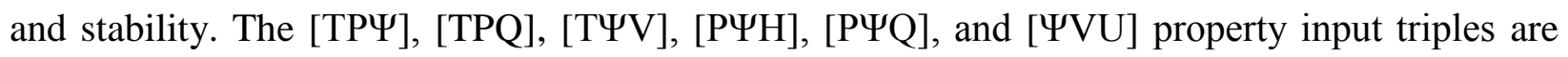
supported.The algorithms developed in this study employ saturation correlations to evaluate initial guesses for iterative solution of two-phase property points and identify single-phase property points. By identifying single-phase state points with this technique,property evaluation time can be decreasedby up to a factor of 5, depending on the input mode. Additionally, this investigation introduced the use of a run-time database of previously evaluated two-phase state points to improve initial guesses for inputs. In a representative study, this approach yielded a $45 \%$ reduction in average property evaluation time. Overall, the developed routines were found to achieve significant reductions in property evaluation times compared to existing property implementations in the EES (Klein, 2014) and REFPROP 9 (Lemmon et al., 2010) programs.

The developed property evaluation algorithms were implemented as a standalone program and studied on a PC with a $2.2 \mathrm{GHz}$ CPU. Including program overhead, average state point evaluation times ranged from 50 to $930 \mu \mathrm{s}$, depending on the input mode. Additionally, the property routines were modified to permit their use in the MATLAB $^{\circledR}$ and $\operatorname{Simulink}^{\circledR}$ environments. A transient, segmental, solution-cooled ammonia-water absorber model was 
developed in Simulink ${ }^{\circledR}$ to demonstrate the use of the developed property routines in a practical engineering application. In $100 \mathrm{~s}$ of simulation time, 780,391 $[\mathrm{P \Psi H}]$ and $[\mathrm{P} \Psi \mathrm{Q}]$ input triples were processed with an average individual property point evaluation time of $192 \mu \mathrm{s}$.

Thus, this study presented strategies that can be employed to significantly improve the performance of ammonia-water mixture property evaluation routines and their application to a practical engineering modeling task. In a future effort, program performance could be further improved by tuning of the under-relaxation factors and other parameters employed in the iterative property evaluation routines. The range of accuracy of the property routines could also be extended by incorporating corrections for decreasedcomponent fugacities at high pressures (as in Ibrahim and Klein (1993)). Additionally, program flexibility could be improved with the development of a generalized routine to evaluate state points given any three independent thermodynamic properties. Finally, the approachesproposed in this study can be applied to other fluid mixtures to accelerate thermal-fluid engineering computations.

\section{Acknowledgements}

Financial support from the U.S. Advanced Research Projects Agency-Energy (ARPA-E) (contract DE-AR0000135) and the U.S. Department of Energy through the Krell Institute (contract DE-FG02-97ER25308) is gratefully acknowledged.The authors also thank Vinodh Viswanathan, a student in the Sustainable Thermal Systems Laboratory (STSL) at the Georgia Institute of Technology, for his assistance in testing the software developed in this study. 


\section{Appendix A. Ammonia-Water Thermodynamic Property Formulation}

The empirical EOS formulation developed by Ziegler and Trepp (1984) is summarized here. This approach begins by defining the specific Gibbs free energy for each component $i$ and phase $j$.

$$
g_{i}^{j}=h_{i}^{j}-T s_{i}^{j}
$$

Expansion of this definition using thermodynamic relations yields the following general form.

$$
g_{i}^{j}=h_{o, i}^{j}-T S_{o, i}^{j}+\int_{o}^{T} c_{\mathrm{p}, i}^{j} d T+\left[v_{i}^{j}-T\left(\frac{\partial v}{\partial T}\right)_{P, i}^{j}\right] d P-T\left[\int_{o}^{T} \frac{c_{\mathrm{p}, i}^{j}}{T} d T-\int_{o}^{P}\left(\frac{\partial v}{\partial T}\right)_{P, i}^{j} d P\right]
$$

Thus, fundamental relations for each phase of each species can be derived using empirical expressions for $v_{i}^{j}(T, p)$ and $c_{\mathrm{p}, i}^{j}(T)$. Ziegler and Trepp (1984)selected the following forms:

$$
\begin{gathered}
v_{i}^{1}=a_{1, i}+a_{2, i} P+a_{3, i} T+a_{4, i} T^{2} \\
c_{\mathrm{p}, \mathrm{i}}^{1}=b_{1, i}+b_{2, i} T+b_{3, i} T^{2} \\
v_{i}^{\mathrm{g}}=\frac{R T}{P}+c_{1, i}+\frac{c_{2, i}}{T^{3}}+c_{3, i} T^{11}+\frac{c_{4, i} P^{2}}{T^{11}} \\
c_{\mathrm{p}, i}^{g}=d_{1, i}+d_{2, i} T+d_{3, i} T^{2}
\end{gathered}
$$

Substitution into EquationA2and evaluation yield expressions for the liquid and vapor molar Gibbs free energies. Note that Equations $(\mathrm{A} 7-8)$ are expressed in terms of reduced variables (Equation A9) where $T_{\mathrm{B}}=100 \mathrm{~K}$ and $P_{\mathrm{B}}=1 \mathrm{MPa}$. 


$$
\begin{aligned}
& g_{\mathrm{r}, i}^{\mathrm{g}}=h_{\mathrm{r}, o, i}^{\mathrm{g}}-T_{\mathrm{r}} s_{\mathrm{r}, o, i}^{\mathrm{g}}+D_{1, i}\left(T_{\mathrm{r}}-T_{\mathrm{r}, o}\right)+\frac{D_{2, i}}{2}\left(T_{\mathrm{r}}^{2}-T_{\mathrm{r}, o}^{2}\right)+\frac{D_{3, i}}{3}\left(T_{\mathrm{r}}^{3}-T_{\mathrm{r}, o}^{3}\right)-D_{1, i} T_{\mathrm{r}} \ln \left(\frac{T_{\mathrm{r}}}{T_{\mathrm{r}, o}}\right) \\
& -D_{2, i} T_{\mathrm{r}}\left(T_{\mathrm{r}}-T_{\mathrm{r}, o}\right)-\frac{D_{3, i}}{2} T_{\mathrm{r}}\left(T_{\mathrm{r}}^{2}-T_{\mathrm{r}, o}^{2}\right)+T_{\mathrm{r}} \ln \left(\frac{P_{\mathrm{r}}}{P_{\mathrm{r}, o}}\right)+C_{1, i}\left(P_{\mathrm{r}}-P_{\mathrm{r}, o}\right)+C_{2, i}\left(\frac{P_{\mathrm{r}}}{T_{\mathrm{r}}^{3}}-4 \frac{P_{\mathrm{r}, o}}{T_{\mathrm{r}, o}^{3}}+3 \frac{P_{\mathrm{r}, o} T_{\mathrm{r}}}{T_{\mathrm{r}, o}^{4}}\right) \\
& +C_{3, i}\left(\frac{P_{\mathrm{r}}}{T_{\mathrm{r}}^{11}}-12 \frac{P_{\mathrm{r}, o}}{T_{\mathrm{r}, o}^{11}}+11 \frac{P_{\mathrm{r}, o} T_{\mathrm{r}}}{T_{\mathrm{r}, o}^{12}}\right)+\frac{C_{4, i}}{3}\left(\frac{P_{\mathrm{r}}^{3}}{T_{\mathrm{r}}^{11}}-12 \frac{P_{\mathrm{r}, o}^{3}}{T_{\mathrm{r}, o}^{11}}+11 \frac{P_{\mathrm{r}, o}^{3} T_{\mathrm{r}}}{T_{\mathrm{r}, o}^{12}}\right)
\end{aligned}
$$

$$
\begin{array}{lll}
T_{r}=T / T_{\mathrm{B}} & P_{r}=P / P_{\mathrm{B}} & g_{r}=g / R T_{\mathrm{B}} \\
h_{r}=h / R T_{\mathrm{B}} & s_{r}=s / R_{\mathrm{B}} & v_{r}=v P_{B} / R T_{\mathrm{B}}
\end{array}
$$

The gas phase of the ammonia-water mixture is assumed to behave as an ideal mixture; therefore, the phasic molar Gibbs free energy can be obtained by combination of the component Gibbs free energies and the entropy of mixing.

$$
g^{\mathrm{g}}=(1-y) g_{\mathrm{w}}^{\mathrm{g}}+y g_{\mathrm{a}}^{\mathrm{g}}+\frac{R T}{M^{\mathrm{g}}}[(1-\bar{y}) \ln (1-\bar{y})+\bar{y} \ln (\bar{y})]
$$

The heat of dilution for liquid ammonia-water mixtures is substantial; therefore, an additional excess energy term is included in the expression for the liquid Gibbs free energy.

$$
g^{1}=(1-x) g_{\mathrm{w}}^{1}+x g_{\mathrm{a}}^{1}+\frac{R T}{M^{1}}[(1-\bar{x}) \ln (1-\bar{x})+\bar{x} \ln (\bar{x})]+g_{\mathrm{E}}
$$

Ziegler and Trepp (1984)selected a three term truncated form of the Redlich and Kister (1948)series expansion for the excess energy of mixing. 


$$
\begin{gathered}
g_{\mathrm{r}, \mathrm{E}}=\frac{\bar{x}(1-\bar{x})}{M^{1}}\left[F_{1}+F_{2}(2 \bar{x}-1)+F_{3}(2 \bar{x}-1)^{2}\right] \\
F_{1}=E_{1}+E_{2} P_{\mathrm{r}}+\left(E_{3}+E_{4} P_{\mathrm{r}}\right) T_{\mathrm{r}}+E_{5} / T_{\mathrm{r}}+E_{6} / T_{\mathrm{r}}^{2} \\
F_{2}=E_{7}+E_{8} P_{\mathrm{r}}+\left(E_{9}+E_{10} P_{\mathrm{r}}\right) T_{\mathrm{r}}+E_{11} / T_{\mathrm{r}}+E_{12} / T_{\mathrm{r}}^{2} \\
F_{3}=E_{13}+E_{14} P_{\mathrm{r}}+E_{15} / T_{\mathrm{r}}+E_{16} / T_{\mathrm{r}}^{2}
\end{gathered}
$$

Expressions for other phasic thermodynamic properties can be derived from the Gibbs free energy equations.

$$
h^{j}=-R T_{\mathrm{B}} T_{\mathrm{r}}^{2}\left[\frac{\partial\left(g_{\mathrm{r}}^{j} / T_{\mathrm{r}}\right)}{\partial T_{\mathrm{r}}}\right]_{P_{\mathrm{r}}} s^{j}=-R\left[\frac{\partial g_{\mathrm{r}}^{j}}{\partial T_{\mathrm{r}}}\right]_{P_{\mathrm{r}}} v^{j}=\frac{R T_{\mathrm{B}}}{P_{\mathrm{B}}}\left[\frac{\partial g_{\mathrm{r}}^{j}}{\partial P_{\mathrm{r}}}\right]_{T_{\mathrm{r}}}
$$

Finally, phase equilibrium at a given temperature and pressure is obtained by equating the liquid and gas chemical potentials of each component, which are defined in EquationA18.

$$
\begin{gathered}
\mu_{\mathrm{w}}^{\mathrm{g}}=\mu_{\mathrm{w}}^{1} \quad \mu_{\mathrm{a}}^{\mathrm{g}}=\mu_{\mathrm{a}}^{1} \\
\mu_{\mathrm{w}}^{1}=g^{1}-\frac{\bar{x}}{M^{1}}\left(\frac{\partial g^{1}}{\partial \bar{x}}\right)_{T, P} \quad \mu_{\mathrm{a}}^{1}=g^{1}+\frac{(1-\bar{x})}{M^{1}}\left(\frac{\partial g^{1}}{\partial \bar{x}}\right)_{T, P} \\
\mu_{\mathrm{w}}^{\mathrm{g}}=g^{\mathrm{g}}-\frac{\bar{y}}{M^{\mathrm{g}}}\left(\frac{\partial g^{\mathrm{g}}}{\partial \bar{y}}\right)_{T, P} \quad \mu_{\mathrm{a}}^{\mathrm{g}}=g^{\mathrm{g}}+\frac{(1-\bar{y})}{M^{\mathrm{g}}}\left(\frac{\partial g^{\mathrm{g}}}{\partial \bar{y}}\right)_{T, P}
\end{gathered}
$$

The dimensionless coefficients employed in the formulation of Ziegler and Trepp (1984) are summarized in Table A1. 
Table A1 - Constants and coefficients for empirical EOS (Ziegler and Trepp, 1984)

\begin{tabular}{|c|c|c|c|c|}
\hline Species & Water $(i=\mathrm{w})$ & $\operatorname{Ammonia}(i=\mathrm{a})$ & \multicolumn{2}{|c|}{ Mixing Rule Coefficients } \\
\hline$A_{1, \mathrm{i}}$ & $2.7487960 \mathrm{E}-2$ & $3.9714230 \mathrm{E}-2$ & $E_{1}$ & $4.1733398 \mathrm{E}+1$ \\
\hline$A_{2, \mathrm{i}}$ & $-1.0166650 \mathrm{E}-5$ & $-1.7905570 \mathrm{E}-$ & $E_{2}$ & $2.4140000 \mathrm{E}-2$ \\
\hline$A_{3, \mathrm{i}}$ & $-4.4520250 \mathrm{E}-3$ & $-1.3089050 \mathrm{E}-2$ & $E_{3}$ & $6.7022850 \mathrm{E}+0$ \\
\hline$A_{4, \mathrm{i}}$ & $8.3892460 \mathrm{E}-4$ & $3.7528360 E-3$ & $E_{4}$ & $-1.1475000 \mathrm{E}-2$ \\
\hline$B_{1, \mathrm{i}}$ & $1.2145570 \mathrm{E}+1$ & $1.6345190 \mathrm{E}+1$ & $E_{5}$ & $6.3608967 \mathrm{E}+1$ \\
\hline$B_{2, \mathrm{i}}$ & $-1.8980650 \mathrm{E}+0$ & $-6.5081190 \mathrm{E}+0$ & $E_{6}$ & $-6.2490768 \mathrm{E}+1$ \\
\hline$B_{3, \mathrm{i}}$ & $2.9119660 \mathrm{E}-1$ & $1.4489370 \mathrm{E}+0$ & $E_{7}$ & $1.7610640 \mathrm{E}+0$ \\
\hline$C_{1, \mathrm{i}}$ & $2.1361310 \mathrm{E}-2$ & $-1.0493770 \mathrm{E}-2$ & $E_{8}$ & $8.6260000 \mathrm{E}-3$ \\
\hline$C_{2, \mathrm{i}}$ & $-3.1692910 \mathrm{E}+1$ & $-8.2882240 \mathrm{E}+0$ & $E_{9}$ & $3.8798300 \mathrm{E}-1$ \\
\hline$C_{3, \mathrm{i}}$ & $-4.6346110 \mathrm{E}+4$ & $-6.6472570 \mathrm{E}+2$ & $E_{10}$ & $-4.7720000 \mathrm{E}-3$ \\
\hline$C_{4, \mathrm{i}}$ & 0 & $-3.0453520 \mathrm{E}+3$ & $E_{11}$ & $-4.6481070 \mathrm{E}+0$ \\
\hline$D_{1, \mathrm{i}}$ & $4.0191700 \mathrm{E}+0$ & $3.6736470 \mathrm{E}+0$ & $E_{12}$ & $8.3637600 \mathrm{E}-1$ \\
\hline$D_{2, \mathrm{i}}$ & $-5.1755500 \mathrm{E}-2$ & $9.9896290 \mathrm{E}-2$ & $E_{13}$ & $-3.5536270 \mathrm{E}+0$ \\
\hline$D_{3, \mathrm{i}}$ & $1.9519390 \mathrm{E}-2$ & $3.6176220 E-2$ & $E_{14}$ & $9.0400000 \mathrm{E}-4$ \\
\hline$h_{r, o, i}^{l}$ & $2.1821141 \mathrm{E}+1$ & $4.8785730 \mathrm{E}+0$ & $E_{15}$ & $2.4361723 E+1$ \\
\hline$h_{r, o, i}^{g}$ & $6.0965058 \mathrm{E}+1$ & $2.6468873 E+1$ & $E_{16}$ & $-2.0736547 \mathrm{E}+1$ \\
\hline$s_{r, o, i}^{l}$ & $5.7334980 \mathrm{E}+0$ & $1.6447730 \mathrm{E}+0$ & & \\
\hline$s_{r, o, i}^{g}$ & $1.3453430 \mathrm{E}+1$ & $8.3390260 \mathrm{E}+0$ & & \\
\hline$T_{r, o, i}$ & $5.0705000 \mathrm{E}+0$ & $3.2252000 \mathrm{E}+0$ & & \\
\hline$P_{r, o, i}^{l}$ & $3.0000000 \mathrm{E}+0$ & $2.0000000 \mathrm{E}+0$ & & \\
\hline
\end{tabular}




\section{Appendix B. Iterative State-Point Solver Algorithms}

\section{B.1. Iterative property solver for [TP $\Psi]$ input mode}

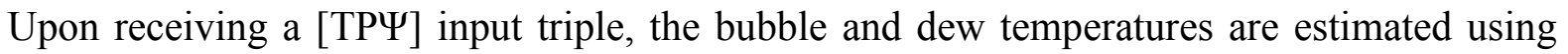
the correlations of Pátek and Klomfar (1995) (EquationsB1-2, coefficients summarized in Table B1).

$$
\begin{gathered}
T_{\text {bub,PK }}=T_{0} \sum_{i=1}^{14} a_{i}(1-\bar{x})^{m_{i}}\left[\ln \left(\frac{p_{0}}{p}\right)\right]^{n_{i}} \\
T_{\text {dew,PK }}(P, y)=T_{0} \sum_{i=1}^{14} a_{i}(1-\bar{y})^{m_{i} / 4}\left[\ln \left(\frac{P_{0}}{P}\right)\right]^{n_{i}}
\end{gathered}
$$

If $T>1.02 T_{\text {dew,PK }}$ or $T<0.98 T_{\text {bub,PK }}$, then the input state can be reliably treated as singlephase, permitting explicit property evaluation in terms of $(T, P, y=\psi)$ for the gas phase or $(T, P$, $x=\psi$ ) for the liquid phase, respectively. Otherwise, iterative property solution is initiated by

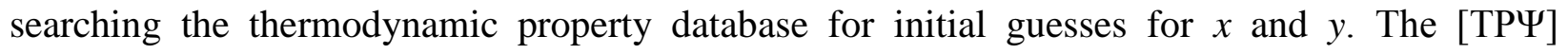
property tree is indexed by the normalized coordinates: $(T(\mathrm{~K}) / 300 \mathrm{~K}, P(\mathrm{~Pa}) / 1 \mathrm{MPa}, \psi)$, and the appropriateness of the closest known property point is quantified in terms of $\rho$ (Equation B3). The particular normalization factors employed in this study $(300 \mathrm{~K}, 1 \mathrm{MPa}, 1)$ were found to provide suitable initial guesses for the thermodynamic ranges employed to evaluate these property routines (Table 1). Different normalization factors may decreasecomputation time in studies focusing on different sections of the thermodynamic state space.

$$
\rho=\sqrt{\left(\frac{T-T_{\mathrm{DB}}}{T}\right)^{2}+\left(\frac{P-P_{\mathrm{DB}}}{P}\right)^{2}+\left(\psi-\psi_{\mathrm{DB}}\right)^{2}}
$$


Table B1 - Constants and coefficients for the bubble and dew temperature correlations (Pátek and Klomfar, 1995)

\begin{tabular}{r|rrr|rrr}
\hline \multirow{2}{*}{ Index } & \multicolumn{3}{|c|}{ Bubble temperature (Eqn. B1) } & \multicolumn{3}{c}{ Dew temperature (Eqn. B2) } \\
\cline { 2 - 6 } & $m_{i}$ & $n_{i}$ & $a_{i}$ & $m_{i}$ & $n_{i}$ & \multicolumn{1}{c}{$a_{i}$} \\
\hline 1 & 0 & 0 & $3.22302 \mathrm{E}+0$ & 0 & 0 & $3.24004 \mathrm{E}+0$ \\
\hline 2 & 0 & 1 & $-3.84206 \mathrm{E}-1$ & 0 & 1 & $-3.95920 \mathrm{E}-1$ \\
\hline 3 & 0 & 2 & $4.60965 \mathrm{E}-2$ & 0 & 2 & $-2.18943 \mathrm{E}-3$ \\
\hline 5 & 0 & 3 & $-3.78945 \mathrm{E}-3$ & 0 & 3 & $-1.43526 \mathrm{E}+0$ \\
\hline 6 & 0 & 4 & $1.35610 \mathrm{E}-4$ & 1 & 0 & $1.05256 \mathrm{E}+0$ \\
\hline 7 & 1 & 0 & $4.87755 \mathrm{E}-1$ & 1 & 1 & $-7.19281 \mathrm{E}-2$ \\
\hline 8 & 1 & 2 & $1.06154 \mathrm{E}-2$ & 2 & 0 & $1.22362 \mathrm{E}+1$ \\
\hline 9 & 2 & 3 & $-5.33589 \mathrm{E}-4$ & 2 & 1 & $-2.24368 \mathrm{E}+0$ \\
\hline 10 & 4 & 0 & $7.85041 \mathrm{E}+0$ & 3 & 0 & $-2.01780 \mathrm{E}+1$ \\
\hline 11 & 5 & 0 & $-1.15941 \mathrm{E}+1$ & 3 & 1 & $1.10834 \mathrm{E}+0$ \\
\hline 12 & 5 & 1 & $-5.23150 \mathrm{E}-2$ & 4 & 0 & $6.44312 \mathrm{E}-1$ \\
\hline 13 & 6 & 0 & $4.89596 \mathrm{E}+0$ & 4 & 2 & $-2.21246 \mathrm{E}+0$ \\
\hline 14 & 13 & 1 & $4.21059 \mathrm{E}-2$ & 5 & 0 & $-7.56266 \mathrm{E}-1$ \\
\hline 15 & & & & 5 & 2 & $-1.35529 \mathrm{E}+0$ \\
\hline 16 & & & & 6 & 0 & $1.83541 \mathrm{E}-1$ \\
\hline 17 & & & & & 2 &
\end{tabular}

$T_{0}=100 \mathrm{~K}, P_{0}=2.0 \mathrm{MPa}$

If $\rho>0.1$, alternate initial guesses are obtained from iterative solution of EquationsB1-2 for $x$ $=x_{\text {bub }}$ and $y=y_{\text {dew }}$. Once the initial guesses are determined, iterative solution of the equilibrium condition $(x$ and $y$ ) can proceed. The residual $\underline{r}$ and Jacobian $\underline{\underline{J}}$ are evaluated at each iteration $k$ using EquationsB4-5.

$$
\underline{r}^{k}=\left[\begin{array}{c}
\mu_{\mathrm{w}}^{1}-\mu_{\mathrm{w}}^{\mathrm{g}} \\
\mu_{\mathrm{a}}^{1}-\mu_{\mathrm{a}}^{\mathrm{g}}
\end{array}\right]^{k}
$$




$$
\underline{J}^{k}=\left[\begin{array}{cc}
\frac{\partial \mu_{\mathrm{w}}^{1}}{\partial x} & -\frac{\partial \mu_{\mathrm{w}}^{\mathrm{g}}}{\partial y} \\
\frac{\partial \mu_{\mathrm{a}}^{1}}{\partial x} & -\frac{\partial \mu_{\mathrm{a}}^{\mathrm{g}}}{\partial y}
\end{array}\right]^{k}
$$

The corrections for $x$ and $y$ at each iteration are evaluated with:

$$
\left[\begin{array}{l}
\Delta x \\
\Delta y
\end{array}\right]^{k}=-\left(\underline{\underline{J}}^{-1} \underline{r}\right)^{k}
$$

An adaptive under-relaxation factor, $\alpha$, is applied to ensure that the phase concentrations remain in the domain $(0,1)$.

$$
\alpha^{k}=\min \left(\left|\frac{1-x^{k}}{2 \Delta x^{k}}\right|,\left|\frac{1-y^{k}}{2 \Delta y^{k}}\right|,\left|\frac{x^{k}}{2 \Delta x^{k}}\right|,\left|\frac{y^{k}}{2 \Delta y^{k}}\right|, 1\right)
$$

The values of $x$ and $y$ are updated at the end of each iteration $k$ using EquationB8.

$$
\left[\begin{array}{l}
x \\
y
\end{array}\right]^{k+1}=\left[\begin{array}{l}
x \\
y
\end{array}\right]^{k}+\alpha^{k}\left[\begin{array}{l}
\Delta x \\
\Delta y
\end{array}\right]^{k}
$$

Iteration terminates when the normalized changes in $x$ and $y$ are sufficiently small: $\left\|\alpha \underline{\underline{J^{-1}}} \underline{r}\right\|_{2}^{k}<10^{-6}$. The quality of the mixture is then evaluated as $Q=(\psi-x) /(y-x)$. If $Q<0$ or $Q>1$, the mixture is assumed to be single-phase liquid $(Q=0)$ or gas $(Q=1)$, depending on whether $T$ is closer to $T_{\text {bub,PK }}$ or $T_{\text {dew,PK }}$, respectively. The remaining thermodynamic properties ( $\phi$ ) are evaluated explicitly using the following expression.

$$
\phi(T, P, x, y, Q)=Q \phi^{\mathrm{g}}(T, P, y)+(1-Q) \phi^{1}(T, P, x)
$$




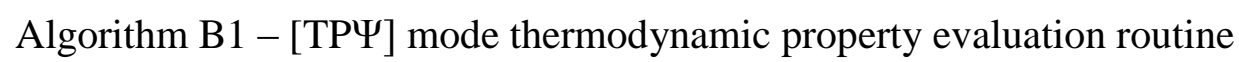

1. Evaluate $T_{\text {bub,PK }}$ and $T_{\text {dew,PK }}$

2. IF $T<1.02 T_{\text {dew,PK }}$ or $T>0.98 T_{\text {bub,PK }}$ THEN

1. Search database for $[\mathrm{TP \Psi}]^{0}$ near $[\mathrm{TP \Psi}]$

2. Evaluate $\rho$

3. IF $\rho>0.1$ THEN evaluate new $[\mathrm{TP} \Psi]^{0}$

4. WHILE $E>10^{-6}$ DO

1. Evaluate $\mu_{\mathrm{w}}^{1}, \mu_{\mathrm{w}}^{\mathrm{g}}, \mu_{\mathrm{a}}^{1}, \mu_{\mathrm{a}}^{\mathrm{g}}$

2. Evaluate $\underline{r}, \underline{J}^{-1}$

3. $\underline{-} \leftarrow-\underline{J}^{-1} \underline{r}$

4. Evaluate $\alpha$

5. $\underline{x} \leftarrow \underline{x}+\alpha \underline{\Delta}$

6. $E \leftarrow \alpha\|\underline{\Delta}\|_{2}$

\section{LOOP}

6. Evaluate $Q$

\section{END IF}

4. IF $\mathrm{Q}<0$ or $\mathrm{Q}>1$ THEN

5. ELSE

1. Evaluate single-phase thermodynamic properties: $(h, v, u, s)(T, P, \Psi)$

1. Evaluate two-phase thermodynamic properties: $(h, v, u s)(T, P, x, y, Q)$

\section{END IF}

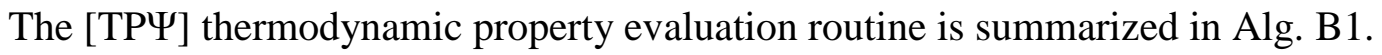

\section{B.2. Iterative property solver for [TPQ] input mode}

As all [TPQ] points lie within the saturation limits $(Q \in[0,1])$, phase selection is not necessary for this input mode. The property evaluation mode begins with iterative solution of EquationsB1-2 to find $x_{\text {bub }}(T, P)$ and $y_{\text {dew }}(T, P)$. The property point database is then searched for the closest known state point as an initial guess using the normalized coordinates $(T(\mathrm{~K})$ / $300 \mathrm{~K}, P(\mathrm{~Pa}) / 1 \mathrm{MPa}, Q)$. The validity of the initial guess is quantified by evaluation of EquationB10. 
Algorithm B2 - [TPQ] mode thermodynamic property evaluation routine

1. Evaluate $x_{\text {bub,PK }}$ and $y_{\text {dew,PK }}$

2. Search database for $[\mathrm{TPQ}]^{0}$ near [TPQ]

3. Evaluate $\rho$

4. IF $\rho>0.1$ THEN evaluate new [TPQ $]^{0}$

1. WHILEE $>10^{-6} \mathbf{D O}$

1. Evaluate $\mu_{\mathrm{w}}^{1}, \mu_{\mathrm{w}}^{\mathrm{g}}, \mu_{\mathrm{a}}^{1}, \mu_{\mathrm{a}}^{\mathrm{g}}$

2. Evaluate $\underline{r}, \underline{J}^{-1}$

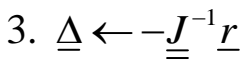

4. Evaluate $\alpha$

5. $\underline{x} \leftarrow \underline{x}+\alpha \underline{\Delta}$

6. $E \leftarrow \alpha\|\underline{\Delta}\|_{2}$

\section{LOOP}

5. Evaluate two-phase thermodynamic properties: $(h, v, u, s)(T, P, x, y, Q)$

$$
\rho=\sqrt{\left(\frac{T-T_{\mathrm{DB}}}{T}\right)^{2}+\left(\frac{P-P_{\mathrm{DB}}}{P}\right)^{2}+\left(Q-Q_{\mathrm{DB}}\right)^{2}}
$$

If $\rho>0.1$, the previously obtained values for $x_{\text {bub }}$ and $y_{\text {dew }}$ are employed as initial guesses for

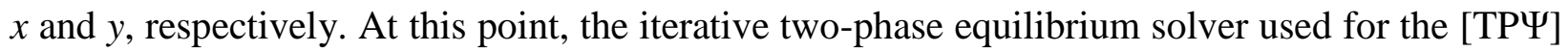
input mode is employed to evaluate $x$ and $y$. The remaining thermodynamic properties are then evaluated explicitly usingEquationB9. A summary of the [TPQ] property evaluation routine is presented in Alg. B2.

\section{B.3. Iterative property solver for $[T \Psi \mathrm{V}]$ input mode}

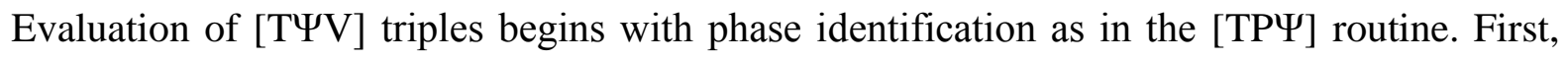
EquationsB1-2 are solved implicitly for $P_{\text {bub,PK }}(T, \psi)$ and $P_{\text {dew,PK }}(T, \psi)$, permitting explicit evaluation of $v_{\text {bub,PK }}=v^{1}\left(T, P_{\text {bub,PK }}, \psi\right)$ and $v_{\text {dew }, \mathrm{PK}}=v^{\mathrm{g}}\left(T, P_{\mathrm{dew}, \mathrm{PK}}, \psi\right)$. If $\quad v>1.1 v_{\mathrm{dew}, \mathrm{PK}}$ or $v<0.98 v_{\text {bub,PK }}$, single-phase iterative solution of $\mathrm{P}$ is sufficient for property evaluation. These particular margins were selected to account for the respectively high and low compressibilities of 
the gas and liquid phases. For example, fluid with specific volume significantly above the approximate dew point predicted by the correlations of Pátek and Klomfar (1995) may correspond to a high quality two-phase mixture in the Ziegler and Trepp (1984) equations of state employed here. However, fluid with specific volume only slightly below the correlated bubble point would most likely correspond to highly compressed liquid in the consistent EOS formulation. If the input specific volume lies within $\left[0.98 v_{\text {bub,PK }}, 1.1 v_{\text {dew,PK }}\right]$, iterative 2-phase property evaluation proceeds, beginning with a database search for initial guesses for $P, Q, x$, and $y$ using the normalized coordinates $\left(T(\mathrm{~K}) / 300 \mathrm{~K}, \psi, v\left(\mathrm{~m}^{3} \mathrm{~kg}^{-1}\right) / 1 \mathrm{~m}^{3} \mathrm{~kg}^{-1}\right)$. The appropriateness of the initial guess is quantified by evaluation of $\rho$ (EquationB11).

$$
\rho=\sqrt{\left(\frac{T-T_{\mathrm{DB}}}{T}\right)^{2}+\left(\psi-\psi_{\mathrm{DB}}\right)^{2}+\left(\frac{v-v_{\mathrm{DB}}}{v}\right)^{2}}
$$

If $\rho>0.1$, alternate initial guesses are obtained by linear interpolation between the saturation conditions (EquationsB12-14).

$$
\begin{gathered}
P^{0}=\frac{v\left(P_{\mathrm{dew}, \mathrm{PK}}-P_{\mathrm{bub}, \mathrm{PK}}\right)+P_{\mathrm{bub}, \mathrm{PK}} v_{\mathrm{dew}, \mathrm{PK}}-P_{\mathrm{dew}, \mathrm{PK}} v_{\mathrm{bub}, \mathrm{PK}}}{v_{\mathrm{dew}, \mathrm{PK}}-v_{\mathrm{bub}, \mathrm{PK}}} \\
x^{0}=\psi \frac{v_{\mathrm{dew}, \mathrm{PK}}-v}{v_{\mathrm{dew}, \mathrm{PK}}-v_{\mathrm{bub}, \mathrm{PK}}} \\
y^{0}=\frac{\psi\left(v-v_{\mathrm{bub}, \mathrm{PK}}\right)+\left(v_{\mathrm{dew}, \mathrm{PK}}-v\right)}{v_{\mathrm{dew}, \mathrm{PK}}-v_{\mathrm{bub}, \mathrm{PK}}}
\end{gathered}
$$

Once the initial guesses are obtained, the [TYV] two-phase iterative solver is initialized. The four unknown thermodynamic quantities $(P, x, y, Q)$ needed for explicit property evaluation are 
not solved simultaneously due to instabilities observed during the program development. Instead, a tiered solver is employed in which $P$ is solved through top-level iterations, and $x, y$, and $Q$ are

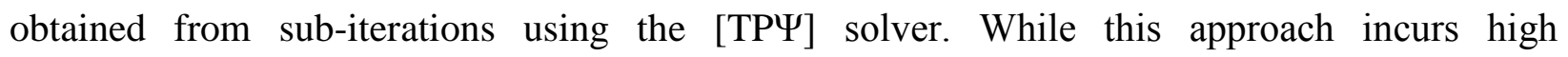
computational cost during initial top-level iterations, once the solution for $P$ has begun to converge, $x, y$, and $Q$ can be obtained with relatively few sub-iterations. Additionally, solution of $x, y$, and $Q$ through sub-iterations ensures that each top-level property evaluation is performed at a thermodynamically permissible (i.e., equilibrium) state point.

Each top level iteration begins with evaluation of $x, y$, and $Q$ using the [TP $\Psi]$ solver. The residual is then evaluated with EquationB15.

$$
r^{k}=v_{\text {in }}-v\left(T_{\text {in }}, P^{k}, x^{k}, y^{k}, Q^{k}\right)
$$

The Jacobian is then evaluated numerically using the current and previous iteration values of $P$ and $v$. A point near $\left(T, P^{0}, v\right)$ is evaluated during the first iteration to permit initial computation of the Jacobian.

$$
J^{k}=-\frac{\partial v}{\partial P} \approx-\frac{v^{k}-v^{k-1}}{P^{k}-P^{k-1}}
$$

The change in $P$ at each iteration is then calculated as: $\Delta P^{k}=-(r / J)^{k}$. A limiter is applied so that the magnitude of $\Delta P$ is less than $P / 2$. The updated pressure and error are evaluated using EquationsB17-18.

$$
P^{k+1}=P^{k}+\alpha^{k} \Delta P^{k}
$$


Algorithm B3 - [TYV] mode thermodynamic property evaluation routine

1. Evaluate $P_{\text {bub,PK }}, P_{\text {dew }, \mathrm{PK}}, v_{\text {bub,PK }}$, and $v_{\text {dew }, \mathrm{PK}}$

2. IF $v<1.1 v_{\text {dew }, \mathrm{PK}}$ or $v>0.9 v_{\text {bub }, \mathrm{PK}}$ THEN

1. Search database for $[\mathrm{T} \Psi \mathrm{V}]^{0}$ near $[\mathrm{T} \Psi \mathrm{V}]$

2. Evaluate $\rho$

3. IF $\rho>0.1$ THEN evaluate new $[\mathrm{T} \Psi \mathrm{V}]^{0}$

4. WHILE $\left|E^{k}\right|>10^{-6}$ DO

1. Solve $(x, y, Q)$ at $\left(T_{\text {in }}, P^{k}, \Psi_{\text {in }}\right)$ with Alg. $1(2.4-2.5)$

2. Evaluate $v^{k}\left(T_{\text {in }}, P, x, y, Q\right)$

3. Evaluate $r, J$

4. $\Delta P \leftarrow-r / J$

5. $\Delta P \leftarrow \operatorname{median}(-P / 2, \Delta P, P / 2)$

6. $P^{k+1} \leftarrow P^{k}+\alpha \Delta P$

7. $E^{k+1} \leftarrow \Delta P / P^{k+1}$

8. Evaluate $\alpha\left(E^{k+1}, E^{k}\right)$

\section{ELSE}

\section{LOOP}

1. Implicit single-phase evaluation of $P$

\section{END IF}

5. IF $\mathrm{Q}<0$ or $\mathrm{Q}>1$ THEN

6. ELSE

1. Evaluate single-phase thermodynamic properties: $(h, u, s)(T, P, \Psi)$

$$
E^{k+1}=\frac{\Delta P^{k}}{P^{k+1}}
$$

The adaptive under-relaxation factor, $\alpha$, is applied to avoid oscillating solutions. $\alpha$ is initialized to 1 , and is updated at each iteration using: $\alpha^{k+1} \leftarrow 0.8 \alpha^{k}$ if $\operatorname{sgn}\left(E^{k}\right) \neq \operatorname{sgn}\left(E^{k-1}\right)$ and $\alpha^{k+1} \leftarrow \max \left(1.25 \alpha^{k}, 1\right)$ if $\operatorname{sgn}\left(E^{k}\right)=\operatorname{sgn}\left(E^{k-1}\right)$. Iteration is terminated when $\left|E^{k}\right|<10^{-6}$, and the remaining unknown thermodynamic quantities are evaluated explicitly using EquationB9. The [TYV] property evaluation routine is summarized in Alg. B3. 


\section{B.4. Iterative property solver for $[\mathrm{P} \Psi \mathrm{H}]$ input mode}

The algorithm employed to evaluate $[\mathrm{P \Psi H}]$ triples is similar to that for $[\mathrm{T} \Psi \mathrm{V}]$ triples because both input sets lack one of the two thermodynamic properties $(T, P)$ employed in the fundamental relations for the individual components. The property evaluation routine begins with computation of $T_{\text {bub,PK }}$ and $T_{\text {dew,PK }}$ using EquationsB1-2. These results are then applied to the evaluation of $h_{\text {bub,PK }}=h^{1}\left(T_{\text {bub,PK }}, P, \psi\right)$ and $h_{\text {dew,PK }}=h^{\mathrm{g}}\left(T_{\text {dew,PK }}, P, \Psi\right)$. If the input enthalpy lies outside of $\left[0.98 h_{\mathrm{bub}, \mathrm{PK}}, 1.02 h_{\mathrm{dew}, \mathrm{PK}}\right]$ single-phase iterative solution of temperature is performed. Otherwise, two-phase solution of $(T, x, y, Q)$ is initiated with a database search for $[\mathrm{P} \Psi \mathrm{H}]^{0}$ near $[\mathrm{P} \Psi \mathrm{H}]$ using the normalized coordinates $\left(P(\mathrm{~Pa}) / 1 \mathrm{MPa}, \psi, h\left(\mathrm{~kJ} \mathrm{~kg}^{-1}\right) / 1000 \mathrm{~kJ}\right.$ $\left.\mathrm{kg}^{-1}\right)$. The applicability of the initial guess from the database is evaluated with EquationB19.

$$
\rho=\sqrt{\left(\frac{P-P_{\mathrm{DB}}}{P}\right)^{2}+\left(\psi-\psi_{\mathrm{DB}}\right)^{2}+\left(\frac{h-h_{\mathrm{DB}}}{h}\right)^{2}}
$$

If $\rho>0.1$, an alternate guess based on linear interpolation between the saturation states is employed (EquationsB20-22).

$$
\begin{gathered}
T^{0}=\frac{h\left(T_{\mathrm{dew}, \mathrm{PK}}-T_{\mathrm{bub}, \mathrm{PK}}\right)+T_{\mathrm{bub}, \mathrm{PK}} h_{\mathrm{dew}, \mathrm{PK}}-T_{\mathrm{dew}, \mathrm{PK}} h_{\mathrm{bub}, \mathrm{PK}}}{h_{\mathrm{dew}, \mathrm{PK}}-h_{\mathrm{bub}, \mathrm{PK}}} \\
x^{0}=\psi \frac{h_{\mathrm{dew}, \mathrm{PK}}-h}{h_{\mathrm{dew}, \mathrm{PK}}-h_{\mathrm{bub}, \mathrm{PK}}} \\
y^{0}=\frac{\psi\left(h-h_{\mathrm{bub}, \mathrm{PK}}\right)+\left(h_{\mathrm{dew}, \mathrm{PK}}-h\right)}{h_{\mathrm{dew}, \mathrm{PK}}-h_{\mathrm{bub}, \mathrm{PK}}}
\end{gathered}
$$




$$
J^{k}=-\frac{\partial h}{\partial T} \approx-\frac{h^{k}-h^{k-1}}{T^{k}-T^{k-1}}
$$

The temperature correction at each iteration is defined as: $\Delta T^{k}=-(r / J)^{k}$. Due to the significant nonlinearity of the $h(T)$ curve in the two-phase region, the $[\mathrm{P \Psi H}]$ routine uses a

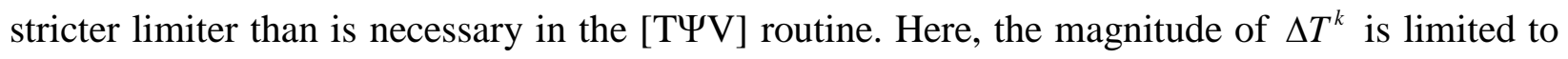
$0.1\left(T_{\mathrm{dew}, \mathrm{PK}}-T_{\text {bub,PK }}\right)$. The temperature is updated at each iteration using EquationB25, in which $\alpha^{k}$ is defined as in the [TYV] routine using the error obtained from EquationB26.

$$
\begin{gathered}
T^{k+1}=T^{k}+\alpha^{k} \Delta T^{k} \\
E^{k+1}=\frac{\Delta T^{k}}{T^{k+1}}
\end{gathered}
$$

Iteration terminates when $\left|E^{k}\right|<10^{-6}$, and the remaining unknown thermodynamic quantities are evaluated explicitly. The formulation for the $[\mathrm{P \Psi H}]$ property evaluation mode is summarized in Alg. B4. 
Algorithm B4 - $[\mathrm{P \Psi H}]$ mode thermodynamic property evaluation routine

1. Evaluate $T_{\text {bub,PK }}, T_{\text {dew,PK }}, h_{\text {bub,PK }}$, and $h_{\text {dew,PK }}$

2. IF $h<1.02 h_{\text {dew,PK }}$ or $h>0.98 h_{\text {bub,PK }}$ THEN

1. Search database for $[\mathrm{P} \Psi \mathrm{H}]^{0}$ near $[\mathrm{P} \Psi \mathrm{H}]$

2. Evaluate $\rho$

3. IF $\rho>0.1$ THEN evaluate new $[\mathrm{P} \Psi \mathrm{H}]^{0}$

4. WHILE $\left|E^{k}\right|>10^{-6}$ DO

1. Solve $(x, y, Q)$ at $\left(T^{k}, P_{\text {in }}, \Psi_{\text {in }}\right)$ with Alg. $1(2.4-2.5)$

2. Evaluate $h^{k}\left(T, P_{\text {in }}, x, y, Q\right)$

3. Evaluate $r, J$

4. $\Delta T \leftarrow-r / J$

5. $\Delta T \leftarrow \operatorname{median}\left(-0.1\left(T_{\text {dew,PK }}-T_{\text {bub,PK }}\right), \Delta T, 0.1\left(T_{\text {dew,PK }}-T_{\text {bub,PK }}\right)\right)$

6. $T^{k+1} \leftarrow T^{k}+\alpha \Delta T$

7. $E^{k+1} \leftarrow \Delta T / T^{k+1}$

8. Evaluate $\alpha\left(E^{k+1}, E^{k}\right)$

\section{LOOP}

\section{ELSE}

1. Implicit single-phase evaluation of $T$

\section{END IF}

5. IF $\mathrm{Q}<0$ or $\mathrm{Q}>1$ THEN

\section{ELSE}

1. Evaluate single-phase thermodynamic properties: $(v, u, s)(T, P, \Psi)$

1. Evaluate two-phase thermodynamic properties: $(v, u, s)(T, P, x, y, Q)$

\section{END IF}

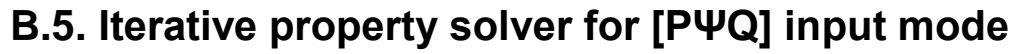

Evaluation of $[\mathrm{P} \Psi \mathrm{Q}]$ property points begins similarly to the $[\mathrm{P} \Psi \mathrm{H}]$ routine with evaluation of $T_{\text {bub,PK }}$ and $T_{\text {dew,PK }}$ using Equations B1-2. The property database is then searched for an initial guess $[\mathrm{P} \Psi \mathrm{Q}]^{0}$ near $[\mathrm{P} \Psi \mathrm{Q}]$ using normalized coordinates $(P(\mathrm{~Pa}) / 1 \mathrm{MPa}, \psi, Q)$, which is tested for applicability by evaluation of EquationB27.

$$
\rho=\sqrt{\left(\frac{P-P_{\mathrm{DB}}}{P}\right)^{2}+\left(\psi-\psi_{\mathrm{DB}}\right)^{2}+\left(Q-Q_{\mathrm{DB}}\right)^{2}}
$$

If $\rho>0.05$, alternate initial guesses are obtained from EquationsB28-30. 


$$
\begin{gathered}
T^{0}=T_{\text {bub,PK }}+\left(T_{\text {dew }, \mathrm{PK}}-T_{\text {bub,PK }}\right) Q \\
x^{0}=\psi(1-Q) \\
y^{0}=1-(1-\psi) Q
\end{gathered}
$$

Iterative solution of $(x, y, T)$ proceeds as in the $[\mathrm{P} \Psi \mathrm{H}]$ mode, using the same limiter and formulations for $\alpha^{k}$ and $E^{k}$. The residual and Jacobian at each top level iteration are defined in EquationsB31-32.

$$
\begin{gathered}
r^{k}=Q_{\text {in }}-Q^{k} \\
J^{k}=-\frac{\partial Q}{\partial T} \approx-\frac{Q^{k}-Q^{k-1}}{T^{k}-T^{k-1}}
\end{gathered}
$$

Upon completion of iteration, the remaining thermodynamic properties are evaluated

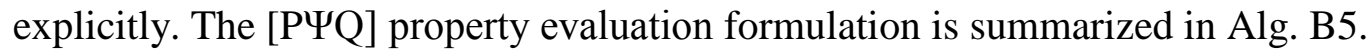

\section{B.6. Iterative property solver for [ $\Psi \mathrm{VU}]$ input mode}

The [YVU] state point definition commonly arises in analyses of control volumes using species, mass, and energy conservation rules. However, evaluation of such state points can be challenging because neither of the parameters $(T, P)$ employed in the fundamental relations for the individual components are known. Additionally, as the saturation correlations employed in this study relate $T$ and $P$, it is difficult to determine a priori if a state point defined in terms of $\psi$, $v$, and $u$ is single- or two-phase. Thus, the [YVU] property routine does not assume the phase of the state point before iterative property evaluation. Instead, the property routine begins by searching the property database for an initial guess using normalized coordinates $\left(\psi, v\left(\mathrm{~m}^{3} \mathrm{~kg}^{-1}\right) /\right.$ 
Algorithm $\mathrm{B} 5-[\mathrm{P \Psi Q}]$ mode thermodynamic property evaluation routine

1. Evaluate $T_{\text {bub,PK }}, T_{\text {dew }, \mathrm{PK}}$

2. Search database for $[\mathrm{P} \Psi \mathrm{Q}]^{0}$ near $[\mathrm{P} \Psi \mathrm{Q}]$

3. Evaluate $\rho$

4. IF $\rho>0.05$ THEN evaluate new $[\mathrm{P \Psi H}]^{0}$

5. WHILE $\left|E^{k}\right|>10^{-6}$ DO

1. Solve $(x, y, Q)$ at $\left(T^{k}, P_{\text {in }}, \Psi_{\text {in }}\right)$ with Alg. $1(2.4-2.5)$

2. Evaluate $r, J$

3. $\Delta T \leftarrow-r / J$

4. $\Delta T \leftarrow \operatorname{median}\left(-0.1\left(T_{\text {dew }, \mathrm{PK}}-T_{\text {bub,PK }}\right), \Delta T, 0.1\left(T_{\text {dew }, \mathrm{PK}}-T_{\text {bub,PK }}\right)\right)$

5. $T^{k+1} \leftarrow T^{k}+\alpha \Delta T$

6. $E^{k+1} \leftarrow \Delta T / T^{k+1}$

7. Evaluate $\alpha\left(E^{k+1}, E^{k}\right)$

\section{LOOP}

7. Evaluate two-phase thermodynamic properties: $(\mathrm{h}, v, u, s)(T, P, x, y, Q)$

$\left.1 \mathrm{~m}^{3} \mathrm{~kg}^{-1}, u\left(\mathrm{~kJ} \mathrm{~kg}^{-1}\right) / 1,000 \mathrm{~kJ} \mathrm{~kg}^{-1}\right)$. Due to the difficulty in predicting appropriate bubble and dew points in the [YVU] mode, the point obtained from the database search is employed as an initial guess for the iterative solver, even if it is not particularly close to the input triple.

Each iteration in the implicit solver begins with evaluation of $(x, y, Q)$ using a modified version of the $[\mathrm{TP \Psi}]$ routine that decreasescomputation time by employing the state point obtained from the previous state point evaluation as an initial guess instead of searching the database. These quantities and the current temperature and pressure $\left(T^{k}, P^{k}\right)$ are employed to evaluate the internal energy and specific volume at each iteration $\left(u^{k}, v^{k}\right)$. The residual vector is then evaluated using EquationB33.

$$
\underline{r}^{k}=\left[\begin{array}{c}
u_{\mathrm{in}}-u^{k} \\
v_{\mathrm{in}}-v^{k}
\end{array}\right]
$$


An update vector for $T$ and $P$ is obtained from:

$$
\left[\begin{array}{c}
\Delta T \\
\Delta P
\end{array}\right]^{k}=-\underline{J}^{k} \underline{r}^{k}
$$

A limiting factor is computed to avoid large changes in $T$ and $P$ over a single iteration, which may lead to solution divergence.

$$
\alpha^{k}=\min \left(1, \frac{5 \mathrm{~K}}{\left|\Delta T^{k}\right|}, \frac{0.2 P^{k}}{\left|\Delta P^{k}\right|}\right)
$$

The temperature and pressure are then updated with the following expression.

$$
\left[\begin{array}{l}
T \\
P
\end{array}\right]^{k+1}=\left[\begin{array}{l}
T \\
P
\end{array}\right]^{k}+\alpha^{k}\left[\begin{array}{l}
\Delta T \\
\Delta P
\end{array}\right]^{k}
$$

Iteration continues until the norm of the most recent correction is sufficiently small $\left(\sqrt{\left(\Delta T^{k} / T^{k}\right)^{2}+\left(\Delta P^{k} / P^{k}\right)^{2}}<10^{-6}\right)$, and the remaining thermodynamic properties $(h, s)$ are 
Algorithm B6 - [YVU] mode thermodynamic property evaluation routine

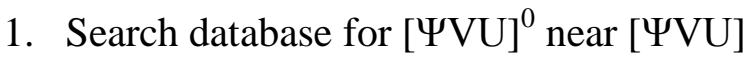

2. WHILE ( $\left(\left|E^{k}\right|>10^{-6}\right)$ DO

1. Solve $(x, y, Q)$ at $\left(T, P, \psi_{\text {in }}\right)$ with modified Alg. 1 (skip steps 2.1-2.3, and use previously evaluated state point instead)

2. Evaluate $u(T, P, x, y, Q)$ and $v(T, P, x, y, Q)$

3. Evaluate $\underline{r}$

4. Solve $(x, y, Q)^{T}$ at $\left(T+\delta T, P, \psi_{\text {in }}\right)$ and solve $(x, y, Q)^{P}$ at $\left(T, P+\delta P, \Psi_{\text {in }}\right)$

5. Evaluate $u^{T}, u^{P}, v^{T}$, and $v^{P}$

6. Update $\underline{\underline{J}}$

7. $\left[\begin{array}{ll}\Delta T & \Delta P\end{array}\right]^{\mathrm{T}} \leftarrow-(\underline{\underline{J}} \underline{r})$

8. Evaluate $\alpha$

9. $T \leftarrow T+\alpha \Delta T, P \leftarrow P+\alpha \Delta P$

10. $E \leftarrow \sqrt{(\Delta T / T)^{2}+(\Delta P / P)^{2}}$

\section{LOOP}

4. IF $\mathrm{Q}<0$ or $\mathrm{Q}>1$ THEN

1. Evaluate single-phase thermodynamic properties: $(h, s)(T, P, \Psi)$

\section{ELSE}

1. Evaluate two-phase thermodynamic properties: $(h, s)(T, P, x, y, Q)$

\section{END IF}

evaluated explicitly. The routine for evaluation of [ $\Psi \mathrm{VU}]$ property points is summarized in Alg.

B6. 


\section{Appendix C. Accuracy of Ammonia-Water Thermodynamic Property Formulation}

The ammonia-water mixture EOS of Ziegler and Trepp (1984) was originally intended for use for: $230 \leq T \leq 500 \mathrm{~K}$ and $20 \leq P \leq 5000 \mathrm{kPa}$. In that range, the predicted bubble-point vapor pressures matched available experimental data (Macriss et al., 1964; Pierre, 1959; Scatchard et al., 1947; Schulz, 1972) to within $~ 3 \%$. Ibrahim and Klein (1993) reported that predicted bubbleand dew-point temperatures (with the Ziegler and Trepp (1984) EOS) matched more recent experimental data (Gillespie et al., 1987) to within $3 \%$ (absolute scale) at $P=138,689$, and 3434 $\mathrm{kPa}$.

Predictions from the present implementation of the Ziegler and Trepp (1984) EOS are compared with those from the more recent EOS formulations of Ibrahim and Klein (1993)(implemented in EES (Klein, 2014)) and Tillner-Roth and Friend (1998a) (implemented in REFPROP (Lemmon et al., 2010)). These two formulations are intended for use over wider ranges of thermodynamic conditions and are derived using newer experimental data. First, 470 state points were evaluated in the range $270 \leq T \leq 450 \mathrm{~K}, 1 \leq P \leq 5000 \mathrm{kPa}$, and $0.01 \leq Q \leq 0.99$. Predicted ammonia mass-fraction values $(\psi)$ were compared between the present implementation and the formulation of Tillner-Roth and Friend (1998a) (average errors over $Q$ ranges presented in Figure C1a).The overall average absolute error in $\psi$ was 0.011 , with slightly smaller errors at higher temperatures and lower pressures.

A second parametric study with 1000 state points was conducted over the range: $1 \leq P \leq$ $5000 \mathrm{kPa}, 0.001 \leq \psi \leq 0.999$, and $0 \leq Q \leq 1$. Here, the present implementation is compared with that of Ibrahim and Klein (1993) because the REFPROP implementation Lemmon et al. (2010) of the Tillner-Roth and Friend (1998a) EOS did not converge for some cases. Resulting temperature values range from 175 - $538 \mathrm{~K}$. Temperature errors (averaged over the quality 

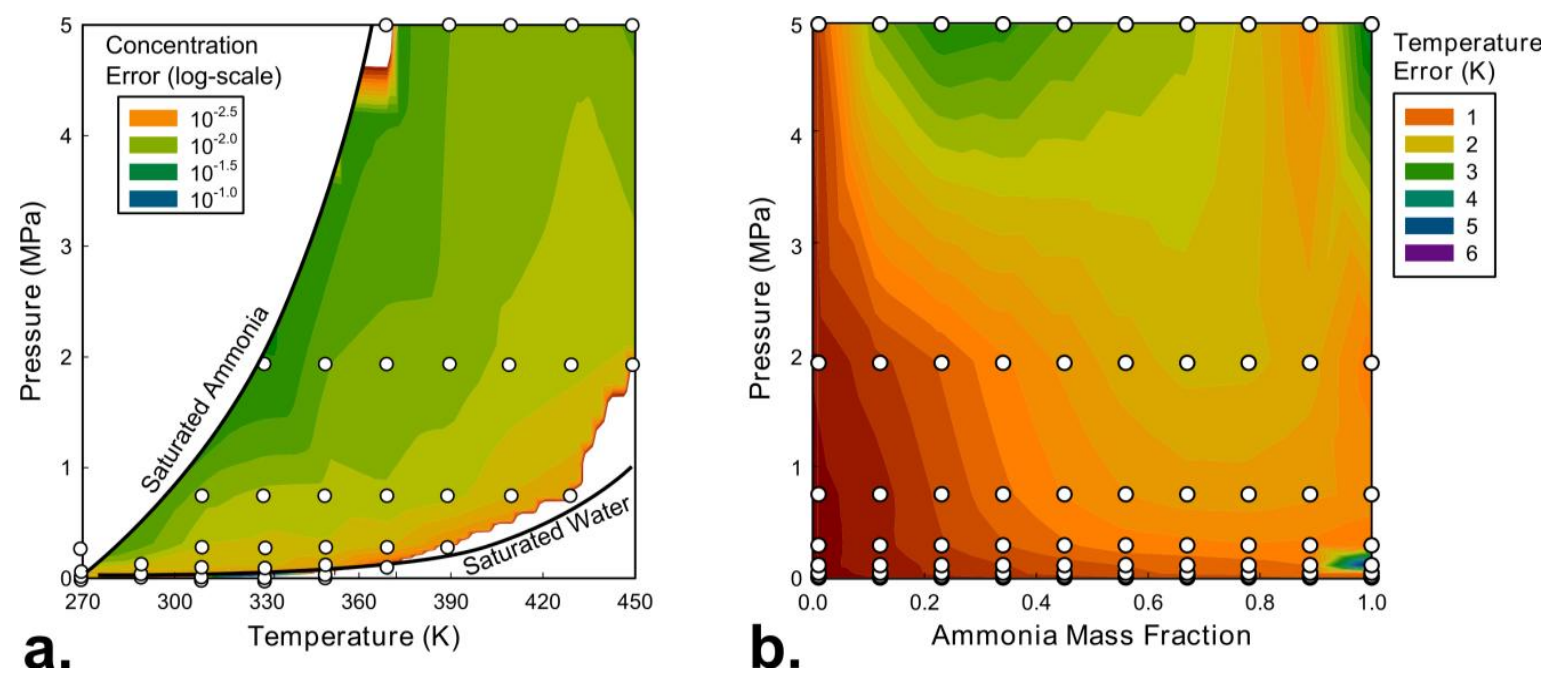

Figure C1 - a. Differences in predicted $\psi$ values between present formulation and that of Tillner-Roth and Friend (1998a) for $(T, P, Q)$ triples (averaged over $Q$ ), b. Differences in predicted $T$ values between present formulation and that of Ibrahim and Klein (1993) for $(P, \psi, Q)$ triples (averaged over Q)

ranges) are presented in Figure $\mathrm{C} 1 \mathrm{~b}$. An overall average temperature error of $0.5 \mathrm{~K}$ is found, with errors generally increasing with pressure (up to $2.3 \mathrm{~K}$ average at $P=5000 \mathrm{kPa}$ ).

Specific accuracy needs vary with applications, and should be considered when selecting a thermodynamic property formulation. Based on results from earlier investigations (Ibrahim and Klein, 1993; Ziegler and Trepp, 1984) and these parametric studies, the following accuracy characteristics apply for $230 \leq T \leq 500 \mathrm{~K}$ and $20 \leq P \leq 5000 \mathrm{kPa}:(T, \psi, Q=0) \rightarrow P \pm \sim 3 \%,(P, \psi, Q$ $=0 / Q=0) \rightarrow T \pm \sim 3 \%,(T, P, Q) \rightarrow \psi \pm \sim 0.01$, and $(P, \psi, Q) \rightarrow T \pm \sim 0.5 \mathrm{~K}$. These uncertainty ranges are expected to be acceptable for applications in ammonia-water absorption refrigeration systems. 


\section{References}

Abovsky, V., 1996. Thermodynamics of ammonia---water mixture, Fluid Phase Equilibria 116, 170-176.

2007. Gas Absorption Refrigeration, From http://www.absreftec.com.

Conde, M.M., 2004. Thermophysical properties of $\{\mathrm{NH} 3+\mathrm{H} 2 \mathrm{O}\}$ solutions for the industrial deisgn of absorption refrigeration equipment, formulation for industrial use. $M$ Conde Engineering, Zurich.

Duan, Z., Møller, N., Weare, J.H., 1996. Equation of state for the NH3-H2O system, Journal of Solution Chemistry 25, 43-50.

El-Sayed, Y.M., Tribus, M., 1985. Thermodynamic properties of water-ammonia mixtures theoretical implementation for use in power cycle analysis, Winter Annual Meeting of the ASME, Miami, FL, pp. 89-95.

Figueira, F.L., Derjani-Bayeh, S., Olivera-Fuentes, C., 2011. Prediction of the thermodynamic properties of $\{$ ammonia + water $\}$ using cubic equations of state with the SOF cohesion function, Fluid Phase Equilibria 303, 96-102.

Ganesh, N.S., Srinivas, T., 2010. Thermodynamic properties of binary mixture for power generation systems, ARPN Journal of Engineering and Applied Sciences 5, 11-25.

Gillespie, P.C., Wilding, W.V., Wilson, G.M., 1987. Vapor-liquid equilibrium measurements on the ammonia-water system from $313 \mathrm{~K}$ to $589 \mathrm{~K}$, AIChE Symposium Series 83, 97-127.

Goyal, A., Rattner, A.S., Garimella, S., 2015. Model-based feedback control of an ammoniawater absorption chiller, Science and Technology for the Built Environment (In press).

Heidemann, R.A., Rizvi, S.S., 1986. Correlation of ammonia-water equilibrium data with various modified Peng-Robinson equations of state, Fluid Phase Equilibria 29, 439-446.

Heppenstall, T., 1998. Advanced gas turbine cycles for power generation: a critical review, Applied Thermal Engineering 18, 837-846.

Herold, K.E., Han, K., Moran, M.J., 1988. AMMWAT: a computer program for calculating the thermodynamic properties of ammonia and water mixtures using a gibbs free energy formulation, ASME Proceedings AES 4, 65-75.

Holcomb, C.D., Outcalt, S.L., 1999. Near-saturation (P,[rho],T) and vapor-pressure measurements of $\mathrm{NH} 3$, and liquid-phase isothermal ( $\mathrm{P},[\mathrm{rho}], \mathrm{T})$ and bubble-point-pressure measurements of NH3+H2O mixtures, Fluid Phase Equilibria 164, 97-106.

Ibrahim, O.M., Klein, S.A., 1993. Thermodynamic properties of ammonia-water mixtures, ASHRAE Transactions: Symposia 21, 1495-1502.

Klein, S.A., 2014. Engineering Equation Solver, V8, F-Chart Software, Madison, WI.

Lemmon, E.W., Huber, M.L., McLinden, M.O., 2010. NIST Standard Reference Database 23:

Reference Fluid Thermodynamic and Transport Properties-REFPROP, 9.0, National Institute of Standards and Technology, Gaithersburg, MD.

Macriss, R.A., Eakin, B.E., Ellington, R.T., Huebler, J., 1964. Physical and thermodynamic properties of ammonia-water mixtures, Institute of Gas Technology Research Bulletin 34, 1-16.

Mejbri, K., Bellagi, A., 2006. Modelling of the thermodynamic properties of the water-ammonia mixture by three different approaches, International Journal of Refrigeration 29, 211-218.

Nowarski, A., Friend, D.G., 1998. Application of the extended corresponding states method to the calculation of the ammonia-water mixture thermodynamic surface, International Journal of Thermophysics 19, 1133-1142. 
Park, Y.M., Sonntag, R.E., 1990. Thermodynamic properties of ammonia-water mixtures: a generalized equation-of-state approach, ASHRAE Transactions: Symposia 96, 150-159.

Pátek, J., Klomfar, J., 1995. Simple functions for fast calculations of selected thermodynamic properties of the ammonia-water system, International Journal of Refrigeration 18, 228-234.

Pierre, B., 1959. Total vapour pressure in bar over ammonia-water solutions, Kylteknisk Tidskrift 14, 89-90.

Redlich, O., Kister, A.T., 1948. Algebraic representation of thermodynamic properties and the classification of solutions, Industrial \& Engineering Chemistry 40, 345-348.

Rizvi, S.S., Heidemann, R.A., 1987. Vapor-Liquid Equilibria in the Ammonia-Water System, Journal of Chemical Engineering Data 32, 183-191.

Rukes, B., Dooley, R.B., 2001. Guideline of the IAPWS formulation 2001 for the thermodynamic properties of ammonia-water mixtures. The International Association for the Properties of Water and Steam, Gaithersburg, MD, USA.

Scatchard, G., Epstein, L.F., Warburton, J., Code, P.J., 1947. Thermodynamic properties saturated liquid and vapor of ammonia-water mixtures, Journal of the ASRE 53, 413-445.

Schulz, S.C.G., 1972. Equations of state for the system ammonia-water for use with computers, International Congress of Refrigeration Proceedings, pp. 431-436.

Stallman, R.M., Fenlason, J., 2009. GNU gprof, 2.21, Free Software Foundation, Boston, MA.

Thorin, E., 2000. Comparison of correlations for predicting thermodynamic properties of ammonia-water mixtures, International Journal of Thermophysics 21, 853-870.

Tillner-Roth, R., Friend, D.G., 1998a. A Helmholtz free energy formulation of the thermodynamic properties of the mixture $\{$ water + ammonia $\}$, Journal of Physical and Chemical Reference Data 27, 63-96.

Tillner-Roth, R., Friend, D.G., 1998b. Survey and assessment of available measurements on thermodynamic properties of the mixture \{water+ammonia\}, Journal of Physical and Chemical Reference Data 27, 45-61.

Tsiombikas, J., 2009. kdtree.

Wilson, T.A., 1925. The total and partial vapor pressures of aqueous ammonia solutions, University of Illinois Bulletin 22, 7-47.

Wucherer, J., von Druck, M., 1932. Temperatur und Zusammensetzung der flüssigen und dampfförmigen Phase von Ammoniak-Wassergemischen im Sättigungszustand, Z. ges. kalte-Ind. 30 .

Ziegler, B., Trepp, C., 1984. Equation of state for ammonia-water mixtures, Revue International du Froid 7, 101-106. 